\title{
A tectonic-rules based mantle reference frame since 1 billion years ago - implications for supercontinent cycles and plate-mantle system evolution
}

5 R. Dietmar Müller ${ }^{1}$, John Cannon ${ }^{1}$, Michael Tetley ${ }^{2}$, Simon E. Williams ${ }^{3}$, Xianzhi Cao ${ }^{5}$, Nicolas Flament ${ }^{4}$, Ömer F. Bodur ${ }^{4}$, Sabin Zahirovic ${ }^{1}$, and Andrew Merdith ${ }^{6}$

${ }^{1}$ EarthByte Group, School of Geosciences, The University of Sydney, NSW 2006, Australia

${ }^{2}$ University of Texas Institute for Geophysics, Jackson School of Geosciences, The University of Texas at Austin, Texas,

1078758 , United States

${ }^{3}$ Department of Geology, Northwest University, Xi'an, 710069, China and EarthByte Group, School of Geosciences, The University of Sydney, NSW 2006, Australia

${ }^{4}$ GeoQuEST Research Centre, School of Earth and Environmental Sciences, University of Wollongong, Northfields Avenue, NSW 2522, Australia

$15{ }^{5}$ Frontiers Science Center for Deep Ocean Multispheres and Earth System; Key Lab of Submarine Geosciences and Prospecting Techniques, MOE and College of Marine Geosciences, Ocean University of China, Qingdao 266100, China ${ }^{6}$ School of Earth and Environment, University of Leeds, Leeds, UK.

Correspondence to: R. Dietmar Müller (dietmar.muller@sydney.edu.au)

20 Abstract. Understanding the long-term evolution of Earth's plate-mantle system is reliant on absolute plate motion models in a mantle reference frame, but such models are both difficult to construct and controversial. We present a tectonic rules-based optimisation approach to construct a plate motion model in a mantle reference frame covering the last billion years and use it as a surface boundary condition for mantle flow models. Our plate motion model results in lithospheric net rotation consistently below $0.25^{\circ} / \mathrm{Myr}$, in agreement with mantle flow models, while trench motions are confined to a relatively narrow range of $-2 /+2 \mathrm{~cm} / \mathrm{yr}$ since $320 \mathrm{Ma}$, during Pangea stability and dispersal. In contrast, the period from $600 \mathrm{Ma}$ to $320 \mathrm{Ma}$, nicknamed here the "zippy tricentenary", displays twice the trench motion scatter compared to more recent times, reflecting a predominance of short and highly mobile subduction zones. Our model supports an orthoversion evolution from Rodinia to Pangea with Pangea offset approximately $90^{\circ}$ eastwards relative to Rodinia - this is the opposite sense of motion compared to a previous orthoversion hypothesis based on paleomagnetic data. In our coupled plate-mantle model a broad network of basal mantle ridges forms between 1000 and 600 Ma, reflecting widely distributed subduction zones. Between 600 and $500 \mathrm{Ma}$ a short-lived degree-2 basal mantle structure forms in response to a band of subduction zones confined to low-latitudes, generating extensive antipodal lower mantle upwellings centred at the poles. Subsequently the northern basal structure migrates southward and morphs into a Pacificcentred upwelling while the southern structure is dissected by subducting slabs and disintegrates into a network of ridges between 500 and 400 Ma. From 400 to 200 Ma, a stable Pacific-centred degree-1 convective planform emerges, lacking an antipodal counterpart due to the closure of the Iapetus and Rheic oceans between Laurussia and Gondwana as well as 
coeval subduction between Baltica and Laurentia and around Siberia, populating the mantle with slabs until 320 Ma when Pangea is assembled. A basal degree-2 structure forms subsequent to Pangea breakup, after the influence of previously subducted slabs in the African hemisphere on the lowermost mantle has faded away. This succession of mantle states is distinct from previously proposed mantle convection models. This Solid Earth Evolution Model for the last 1000 million years (SEEM1000) forms the foundation for a multitude of spatio-temporal data analysis approaches.

Short summary. We have built a community model for the evolution of the Earth's plate-mantle system. Created with open-source software and an open-access plate model, it covers the last billion years, including the formation, breakup and dispersal of two supercontinents, and the creation and destruction of numerous ocean basins. The model allows us to 'see' into the Earth in 4D, and helps us unravel the connections between surface tectonics and the "beating heart" of the Earth, its convecting mantle.

\section{Introduction}

\subsection{Relative versus absolute plate motions}

Plate tectonics unifies our understanding of the evolving solid Earth, the ocean basins, landscapes, and the evolution of life. Since the advent of the plate tectonic theory enormous progress has been made in mapping the relative motions of the plates through time, constrained by magnetic anomaly and fracture zone data in the ocean basins, and a variety of geological, geophysical and paleomagnetic data on the continents (see summary by Cox and Hart, 2009). Nonetheless, absolute plate motions, i.e. the motions of the plates relative to a fixed reference system, such as the spin

55 axis of the Earth or the mesosphere, have been much more difficult to constrain. Both the paleolatitude of a plate as well as its paleo-meridian orientation can be calculated using paleomagnetic data, providing a paleomagnetic pole for a given plate (Cox and Hart, 2009). However, since the Earth's magnetic dipole field is radially symmetric, paleo-longitudinal information cannot be determined from paleomagnetic data alone, unless further assumptions are made (Torsvik and Cocks, 2019). For relatively recent geological times (Late Cretaceous to present), seamount chains as well as continental

60 volcanic formations with a linear age progression can be used to restore plates to their paleo-positions (including paleolatitude and -longitude), with the assumption that surface hot spots resulting from intersections of mantle plumes with the surface, are either fixed relative to each other or moving slowly with respect to each other (Koppers et al., 2021). Various alternative time-dependent regional and global absolute plate motion models based on hotspot tracks have been developed over the past decades, with some based on hotpot track data alone (e.g., Maher et al., 2015; Wessel and

65 Kroenke, 2008) while others reflect a combination of relative plate motion and mantle convection models (e.g., O'Neill et al., 2005; Steinberger, 2000). Hotspot track-based models for recent geological times can be combined with models based on paleomagnetic data for earlier times, forming "hybrid models" (Torsvik et al., 2008). The difficulties involved in constructing hotspot reference frames, and their lack of robustness for pre-Cretaceous times, reflecting a shortage of 
preserved age-dated hotspot tracks, led to the idea of a subduction reference frame. This follows the assumption that slabs sink vertically through the entire mantle, allowing the location of past subduction zones to be reconstructed based on global mantle tomographic models (Van Der Meer et al., 2010). However, the empirical "longitudinal correction" applied to the plates in such models differs significantly with plate positions derived from hotspot track data (Butterworth et al., 2014). Domeier et al. (2016) tested the concept of a subduction reference frame concept using a range of tomographic models and concluded that the method may be used for reconstructions back to $130 \mathrm{Ma}$, reflecting imaged slabs down to a depth of $2300 \mathrm{~km}$.

\subsection{Large Low Shear Velocity Provinces as longitudinal markers?}

Considering that neither age-progressive hotspot tracks nor subducted slabs are useful for reconstructing the past positions of plates before the Cretaceous Period, and the considerable challenge of reconstructing paleolongitude from paleomagnetic data, Torsvik and Cocks (2019) built on the idea of Large Low Shear Velocity Province (LLSVP) stability put forward in Burke and Torsvik (2004). LLSVPs were regarded as useful in this context as their edges were proposed to act as "plume generation zones", offering an avenue to align age-dated large igneous provinces (LIPs) and kimberlites with the present-day edges of LLSVPs. This hypothesis is built on the assumption that LIPs and kimberlites are the product of plumes rising from LLSVP boundaries, which are stationary through time (Burke and Torsvik, 2004). This offers a reproducible and quantifiable method of adding a longitudinal correction to reconstructed plates, thus providing an apparent solution to reconstructing longitude. Le Pichon et al. (2019) also built an absolute reference frame based on an assumption of stationary deep mantle structures, back to $400 \mathrm{Ma}$. However, the basic tenet of these approaches, namely the long-term stability of LLSVPs, has been challenged. Recent mantle tomographic images, combined with fluid mechanic constraints, have resulted in a view that LLSVPs are composed of bundles of thermochemical upwellings enriched in denser than average material (Davaille and Romanowicz, 2020). Only when tomographic models are filtered to long wavelengths do these structures take on the appearance of homogenous, uniform and potentially stable provinces (see also Schuberth et al., 2009; Tkalčić et al., 2015). These models and observations, as well as mantle flow models (e.g., Zhang et al., 2010; Zhong and Liu, 2016; Cao et al., 2021a; Davies et al., 2015; Garnero and Mcnamara, 2008; Flament et al., 2017), indicate that the shape of LLSVPs is controlled by the distribution of subducted slabs and the position of LLSVPs relative to them, implying that LLSVP structures and their boundaries are mobile. Based on mantle flow models, Zhang et al. (2010) concluded that the African LLSVP is unlikely to have existed in its current form before $230 \mathrm{Ma}$, while Mitchell et al. (2012) suggested, based on distribution patterns of virtual geomagnetic poles, that neither the African nor the Pacific antipodal upwellings existed before the creation of Pangea. Doucet et al. (2020b) used the geochemical composition of plume-related basalts to argue for a dynamic relationship between deep mantle structures and plate tectonic evolution. These inferences remain to be further tested, but the apparent unlikelihood of LLSVP stability over long geological time periods challenges the usefulness of the method proposed by Torsvik and Cocks (2019) as a universal solution for reconstructing the longitude of plates. 
Possible alternative modes of supercontinent formation include: (1) closing of the youngest ocean basin on the same hemisphere as the last supercontinent ("introversion", re-closing the Atlantic Ocean from the present configuration), (2) closing of the older antipodal ocean basin ("extroversion", closing the Pacific Ocean from the present configuration) and (3) closing an ocean basin orthogonal to the direction of opening of the last ocean basin ("orthoversion", e.g. closing the Arctic Ocean from the present configuration) (Evans et al., 2016; Murphy and Nance, 2003; Murphy et al., 2009). Following these ideas, Mitchell et al. (2012) proposed an alternative method to obtain paleo-longitude from paleomagnetic data across supercontinent cycles. They utilised the record of oscillatory true polar wander, the rotation

110 of the Earth about the equatorial minimum moment of inertia, as expressed in apparent polar wander paths, to propose that subsequent supercontinents are roughly separated from each other by $90^{\circ}$ of longitude (Mitchell et al., 2012). This orthoversion reconstruction effectively assembles a new supercontinent above one of the downwelling subduction girdles surrounding the previous supercontinent. While this method provides a conceptual model for absolute plate motions, it falls short of being useful for deriving an actual mantle reference frame through time (Torsvik and Cocks, 2019), and it

115 also assumes the occurrence of true polar wander episodes rather than deriving them independently. An additional uncertainty in Mitchell et al.'s (2012) method is that it cannot uniquely determine whether the path from one supercontinent to the next is from west to east or vice versa. To understand the geodynamic history of continents after supercontinent breakup it is imperative to have a continuous time series of absolute plate motions and to know whether the western or the eastern borders of a dispersing supercontinent move across a major downwelling driven by slabs sinking in the mantle.

\subsection{Net lithospheric rotation and trench migration}

The net rotation of the lithospheric shell of the Earth relative to the underlying mantle owes its origin to lateral variations in upper mantle viscosity and mantle structure (Rudolph and Zhong, 2014; Ricard et al., 1991). Many published absolute plate motion models suffer from plate velocity artefacts, typically resulting in excessive net lithospheric rotation magnitudes. Absolute plate motion models are based on fitting observations and some models over-fit observations, or fit the wrong trends within data from volcanic chains (see Schellart et al., 2008, for a discussion), providing results that geodynamicists consider to be problematic and difficult to reconcile with our knowledge of mantle rheology (e.g., Rudolph and Zhong, 2014). As a consequence, mantle flow modellers often convert a plate tectonic model into a socalled no-net-rotation (NNR) reference frame (e.g. Mao and Zhong, 2021), in which the net rotation of the entire lithosphere relative to the mantle is set to zero at all times. Speed limits to lithospheric net rotation have been proposed based on mantle flow modelling that led to the conclusion that net rotation should be below 0.2-0.3\%/Myr (Becker, 2006; Conrad and Behn, 2010), but not necessarily zero. Using a low net rotation threshold for building an absolute plate motion model, as opposed to assuming that it is zero, implicitly acknowledges that the viscosity below the lithosphere is not constant everywhere, an often-cited criticism of NNR reference frames (Le Pichon et al., 2019). Here we consider a NNR 

comply with geodynamic constraints (Becker, 2006; Conrad and Behn, 2010). Williams et al. (2015) analysed a set of alternative absolute plate motion models and proposed that global optimization of trench migration characteristics should be considered as an additional criterion in the construction of absolute plate motion models, a strategy that we follow here. Williams et al. (2015) followed the insights of Schellart et al. (2008) who observed that most trenches mostly roll back slowly at speeds of $\sim 0-2 \mathrm{~cm} / \mathrm{yr}$ at present-day, with trench advance being extremely rare.

\subsection{Alternative approach for mantle reference frame construction}

All absolute reference frames discussed above fall in the category of mantle reference frames, i.e. they are designed to estimate the position of plates relative to the mantle through time, as opposed to the spin axis. Unlike the spin axis, the convecting mantle, does not provide a stable, fixed reference system through time. A mantle reference frame attempts to isolate the motions of plates relative to the mantle, given as plate rotations relative to the Earth's spin axis, which is assumed to be fixed. Such a reference frame is therefore agnostic of true polar wander (TPW), a solid-body rotation of the Earth with respect to its spin axis causing geographic poles to "wander" (Raub et al., 2007). Paleomagnetic data map both the motions of the plates relative to the mantle as well as true polar wander, and can thus be used to restore the plates in terms of their "true" latitudinal positions through time, which is useful for paleoclimate studies. However,

150 when reconstructed virtual geomagnetic poles derived from paleomagnetic data do not constrain paleolongitude due to the radial symmetry of the Earth's magnetic field (Cox and Hart, 2009), and therefore cannot be used to track the movement of the plates across mantle upwellings and downwellings, unless additional assumptions are made-see Section 1.2 in Torsvik and Cocks (2019). In contrast, an ideal mantle reference frame provides both constraints on both paleolatitudes and paleolongitudes of plates relative to the mantle. However, as it does not consider TPW, it does not provide paleogeographic reconstructions useful for paleoclimate studies (Van Hinsbergen et al., 2015). These two types of reference frames are complementary to each other.

To overcome the limitations of traditional mantle reference frames, Tetley et al. (2019) presented a new method applying a joint global inversion to evaluate the contribution of multiple time-dependent absolute plate motion constraints including fit to age-progressive hotspot tracks, optimizing subduction zone migration behaviours and minimizing rates of net lithospheric rotation. This approach explicitly excludes true polar wander, as the method is deliberately aimed at reconstructing the plates relative to the convecting mantle. The method automatically provides both paleo-latitudes and -longitudes relative to the mantle, thus providing a mantle reference frame, expressed as rotations of the plates relative to the spin axis of the Earth that is assumed to be stationary. This approach has been refined for the application in this paper by including evaluation of continental velocities relative to the mantle as additional criterion. Tectonic rules-based plate motion model optimisation can be applied to any plate motion model with continuous closing plate boundaries through time (Gurnis et al., 2012). 
Our aim is to derive a mantle reference frame for the plate motion model of Merdith et al. (2021), extending the motion model suitable for plate-mantle system simulations, and allows us to test the orthoversion hypothesis suggested by Mitchell et al. (2012) independently of any reliance on paleomagnetic data. It also allows us to evaluate the difference between the widely used NNR reference frame approach and a more complex application of tectonic rules to reference frame construction, aiming to minimise net rotation jointly with other key parameters. Lastly, it allows us to design a

plate-mantle system model to understand how the deep mantle structure responds to plate motions following a set of tectonic rules. For instance, we can test the hypothesis by Mitchell et al. (2012) that the African and Pacific LLSVPs did not exist before Pangea assembled.

\section{Methods}

\subsection{Mantle reference frame optimisation}

It needs to be stated in the outset that prior to the assembly of Pangea we have much less constraints on the relative positions of plates as compared to more recent times. To render mantle reference frame construction tractable, we have to leave relative plate motions unaltered and focus on optimising a single, global reference frame. Our workflow for absolute plate motion model construction follows the iterative method outlined in Tetley et al. (2019) (Fig. 1). For a given iteration, the approach starts with perturbing an initial absolute Euler rotation (pole latitude, pole longitude and angle magnitude) for a given reference continent or plate, and then calculates a series of fit metrics with selected constraining data using objective (or cost) functions. This process continues until a global minimum is found. For this study, we use continental Africa as the reference (as it forms the base of the plate model rotation tree of Merdith et al. (2021)). Following Tetley et al. (2019), we calculate fit metrics computed from evaluating (1) lithospheric net rotation rate (NR), (2) trench migration rate (TM), and (3) the fit of present-day hotspots to the major age-progressive hotspot tracks for the period of 0-80 Ma only (HS). However, in addition to the above, we extend the existing method and also compute a fourth constraining criterion: (4) median global continental absolute plate velocity (PV). We introduce the inclusion of continental absolute plate velocities as additional criterion to prevent mean oceanic plate velocities based on synthetic plates from potentially inducing unreasonably high continental speeds globally, as the deep-time reconstructions used here include large swathes of reconstructed ocean floor that is now subducted, based on a variety of indirect pieces of geological evidence (Merdith et al., 2021).

The four constraining criteria are applied to the absolute plate motion model optimization with the following assumptions/bounds: (1) rates of net lithospheric rotation (NR) are minimized but non-zero, (2) global trench migration velocities are minimized, favouring trench retreat over trench advance, (3) spatio-temporal misfit between plate motion 
model and present-day hotspot chains is minimized, and (4) global continental median plate speed remains $<6 \mathrm{~cm} / \mathrm{yr}$, based on continental plate speed statistics reported in Zahirovic et al. (2015). The contribution of individual optimization parameters to the overall inversion are initially scaled by relative magnitude and then weighted by empirically determined weights. For times older than $80 \mathrm{Ma}, \mathrm{NR}=1, \mathrm{TM}=0.5, \mathrm{PV}=0.5, \mathrm{HS}=0(0-80 \mathrm{Ma}, \mathrm{NR}=\mathrm{TM}=\mathrm{PV}=\mathrm{HS}=1)$. From this optimised plate motion model, we then reconstruct the age-area distribution of the ocean floor, based on the evolving plate boundary topologies and rotations, following the method by Williams et al. (2021).

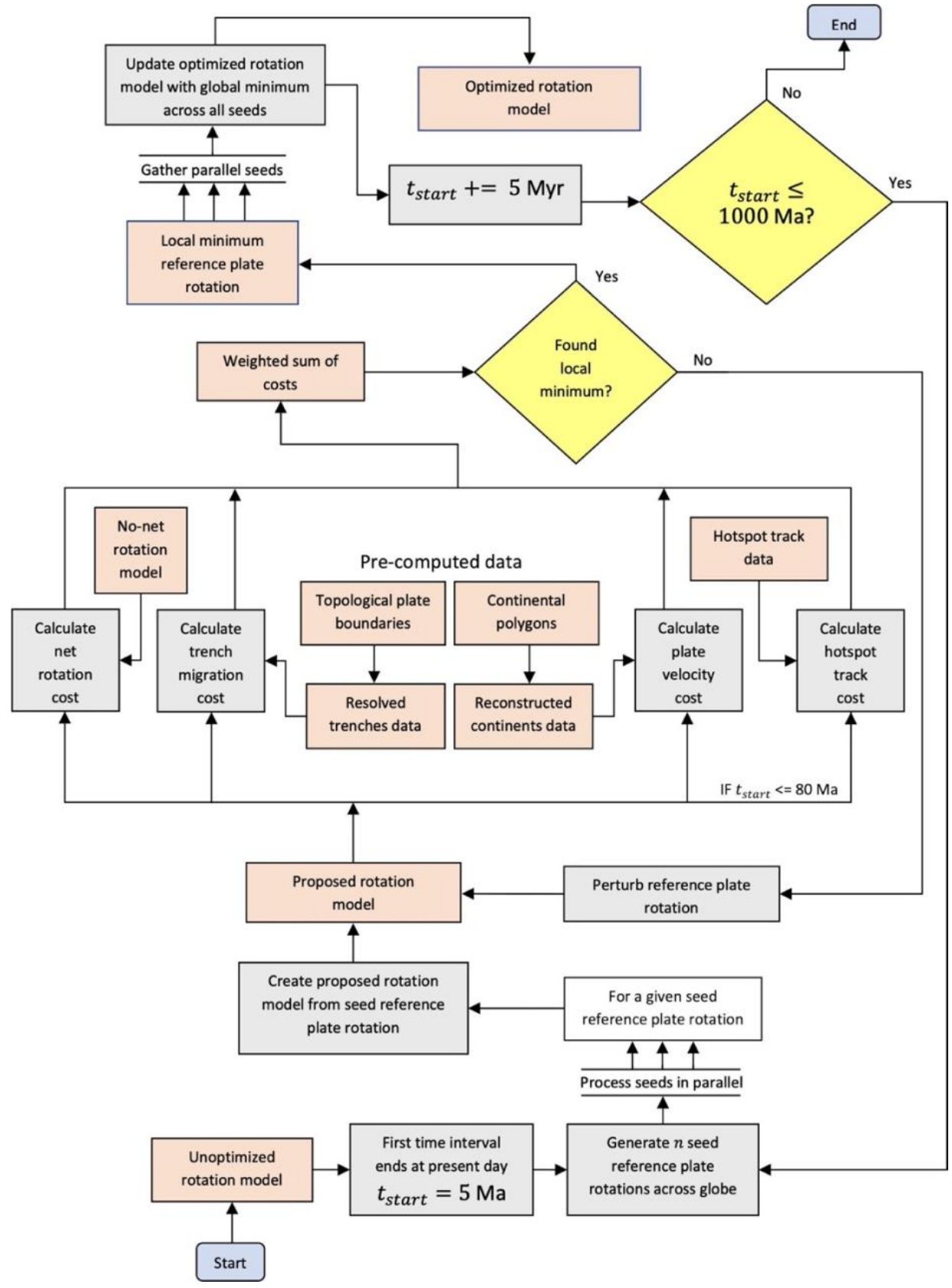


Figure 1. Optimization workflow including decisions (yellow diamonds) and directing flow through processes (rectangular grey boxes) that accept input and produce output data (orange boxes). The beginning and end of the workflow are denoted by light blue boxes with rounded edges. The workflow sequentially optimizes absolute plate motion in $5 \mathrm{Myr}$ time intervals starting at present day and progressing backwards in time until $1000 \mathrm{Ma}$. Within each time interval the motion of a reference plate (and thereby the absolute motion of all plates) is optimized by perturbing its rotation while iteratively minimizing the cost of an objective function. The reference plate is Africa between 550-0 Ma and Laurentia between 1000-550 Ma. Global optimisation in the current time interval is initiated by generating 400 rotations with which

215 to seed local optimizations. Each seed is generated from the reference plate rotation optimized in the preceding time interval by retaining its rotation angle but distributing its rotation pole (latitude and longitude) to 400 uniform locations across the globe. To take advantage of parallel processing we distribute these 400 seeds in parallel across multiple computational nodes, with each node performing a local optimization of a single seed, and the results from all nodes gathered to find the globally minimal reference plate rotation for the current time interval. The objective function (minimized during optimisation) consists of four separate weighted cost functions using the perturbed rotation model as input: (1) misfit distances of hotspot trails (between 0-80 Ma), (2) net rotation of reference plate with an extra penalty if below 0.08 or above 0.20 degrees/Myr (for efficiency the net rotation is calculated relative to a no-net rotation model), (3) trench migration calculated as mean magnitude of trench-orthogonal velocity sampled uniformly along all trenches with an extra penalty if the mean magnitude exceeds $30 \mathrm{~mm} / \mathrm{yr}$ (for efficiency we only resolve trenches from topological plate boundaries once per time interval), and (4) plate velocity magnitude calculated as median velocity of uniformly sampled points inside continents with an extra penalty if magnitude exceeds $60 \mathrm{~mm} / \mathrm{yr}$ (for efficiency we only reconstruct continental polygons and their contained sample points once per time interval).

\subsection{Mantle convection modelling}

We model mantle convection using the extended-Boussinesq approximation in a version of CitcomS (Zhong et al., 2008) which has been modified for progressive assimilation of surface boundary conditions from plate reconstructions (Bower et al., 2015). We build the thermal structure of the lithosphere using reconstructed seafloor ages and a half-space cooling model with maximum seafloor age set to 80 Myr. Similarly, we build the thermal structure of subducting slabs from the surface to $350 \mathrm{~km}$ depth with a dip angle of $45^{\circ}$ using seafloor ages at $1 \mathrm{Myr}$ intervals. We apply an isothermal $(\mathrm{T}=273 \mathrm{~K}$ ) and kinematic (plate velocities exported from the reconstructions) boundary condition at the surface, and an isothermal $(\mathrm{T}=3373 \mathrm{~K})$ and free-slip boundary condition at the CMB. Slabs are initially built from surface to $1000 \mathrm{~km}$ depth, with dip angles of $45^{\circ}$ above $425 \mathrm{~km}$ depth and $90^{\circ}$ below.

We consider 4 mantle model cases: cases OPT1 and OPT2 use our optimized reconstruction as time-dependent boundary conditions, case PMAG uses the reconstruction from Merdith et al. (2021) which is in a paleomagnetic reference frame, and case NNR uses the same reconstruction except with net lithospheric rotations removed (i.e., a no- 
net-rotation reference frame). The initial condition includes a 113-km-thick denser basal layer. The excess density is defined by the buoyancy ratio $\mathrm{B}=\delta \rho_{\mathrm{ch}} /(\rho \alpha \Delta \mathrm{T})$, where $\rho$ is the density, $\alpha$ is the coefficient of thermal expansivity, $\Delta \mathrm{T}=$ $3100 \mathrm{~K}$ is the temperature difference across the mantle, and $\delta \rho_{\mathrm{ch}}$ is density contrast disregarding thermal effects. The buoyancy ratio B is 0.25 for case OPT1, and 0.325 for other cases (Table 1), which respectively corresponds to an excess density of about $\sim 1 \%\left(\delta \rho_{\text {ch }}=56.8 \mathrm{~kg} \mathrm{~m}^{-3}\right)$ and $\sim 1.3 \%\left(\delta \rho_{\text {ch }}=73.8 \mathrm{~kg} \mathrm{~m}^{-3}\right)$ for the basal layer, if we take $\rho=5546 \mathrm{~kg} \mathrm{~m}^{-3}$ (the average value of the bottom $100 \mathrm{~km}$ above the CMB from Preliminary Reference Earth Model (Dziewonski and Anderson, 1981)), and $\alpha=1.32 \times \mathbf{1 0}^{-5} \mathrm{~K}^{-1}$ (the average value of the bottom $100 \mathrm{~km}$ above the CMB. The composition field is tracked with tracers using the ratio tracer method (Mcnamara and Zhong, 2004; Tackley and King, 2003). Before the main calculation, the 1000 Ma plate configuration was applied during a $250 \mathrm{Myr}$ warm-up phase.

The convective vigour is controlled by the Rayleigh number: $R a=\alpha_{0} \rho_{0} g_{0} \Delta T h_{M}^{3} / \kappa_{0} \eta_{0}=7.8 \times 10^{7}$, where $\alpha_{0}=3 \times \mathbf{1 0}^{-5} \mathrm{~K}^{-1}$ is the reference coefficient of thermal expansivity at the surface, $\rho_{0}=4,000 \mathrm{~kg} \mathrm{~m}^{-3}$ is the density, $g_{0}=9.81 \mathrm{~m} \mathrm{~s}^{-2}$ is the acceleration of gravity at the surface, and $h_{M}=2,867 \mathrm{~km}$ is the thickness of the mantle. The dissipation number is $\boldsymbol{D i}=\boldsymbol{\alpha}_{\mathbf{0}} \boldsymbol{g}_{\mathbf{0}} \boldsymbol{R}_{\mathbf{0}} / \boldsymbol{C}_{\boldsymbol{P}_{\mathbf{0}}}=\mathbf{1 . 5 6}$, where $\boldsymbol{C}_{\boldsymbol{P}_{\mathbf{0}}}=1,200 \mathrm{~J} \mathrm{~kg}^{-1} \mathrm{~K}^{-1}$ is the reference heat capacity. The rate of internal heating for the whole model is $H=33.6 \mathrm{TW}$. Viscosity is temperature, composition and depth dependent:

$$
\eta=\eta(r) \eta_{0} \eta_{\mathrm{C}} \exp \left(\frac{E_{\eta}+\rho_{0} g Z_{\eta}\left(R_{0}-r\right)}{R\left(T+T_{o f f}\right)}-\frac{E_{\eta}+\rho_{0} g Z_{\eta}\left(R_{0}-R_{c}\right)}{R\left(T_{C M B}+T_{o f f}\right)}\right)
$$

where $\eta(r)$ is a depth-dependent pre-factor with values $0.02,0.002,0.02,0.2$ for mantle above $160 \mathrm{~km}$, between 160-310 $\mathrm{km}$, between $310-660 \mathrm{~km}$ and below $660 \mathrm{~km}$, respectively. $\eta_{0}=1.1 \mathrm{e} 21 \mathrm{~Pa} \mathrm{~s}$ is the reference viscosity, $\eta_{C}$ is the compositional viscosity pre-factor: 1, 100, 10 for ambient mantle, continental lithosphere and basal layer, respectively, in the initial condition. $E_{\eta}=283.5 \mathrm{~kJ} \mathrm{~mol}^{-1}$ is the activation energy, $Z_{\eta}=2.1 \mathrm{~cm}^{3} \mathrm{~mol}^{-1}$ is the activation volume, $g$ is the acceleration of gravity, $R_{0}=6,371 \mathrm{~km}$ is the radius of the Earth, $r$ is the radius, $R=8.31 \mathrm{~J} \mathrm{~mol}^{-1} \mathrm{~K}^{-1}$ is the universal gas constant, $T$ is the temperature, $T_{\text {off }}=496 \mathrm{~K}$ is a temperature offset, and $R_{C}=3,504 \mathrm{~km}$ is the radius of the core. $E_{\eta}$ and $T_{\text {off }}$ are selected to obtain viscosity variations by three orders of magnitude as a function of temperature (Flament, 2019). The model consists of $\sim 13$ million nodes $(129 \times 129 \times 65 \times 12)$, with radial mesh refinement to obtain slightly higher resolutions at the surface $(\sim 50 \times 50 \times 15 \mathrm{~km})$ and CMB $(\sim 28 \times 28 \times 27 \mathrm{~km})$, and a lower resolution in the mid-mantle $(\sim 40 \times 40 \times 100 \mathrm{~km})$.

\subsection{Mantle structure cluster analysis}

To facilitate an objective, quantitative comparison between 3D volumes of seismic velocity and model temperature fields in the lower mantle, we reduce these $3 \mathrm{D}$ volumes into $2 \mathrm{D}$ maps using vertical volume averaging (see 
Flament, 2019; Lekic et al., 2012). We use $k$-means clustering (Macqueen, 1967) to separately classify temperature and seismic velocity anomalies in the lower mantle into two groups. Profiles for each field are extracted beneath $\sim 200,000$ equally spaced points (with average distance $0.45^{\circ}$ ) at 31 depths between $1000 \mathrm{~km}$ and $2800 \mathrm{~km}$ (Lekic et al., 2012), and then separated into two clusters according to the variation in the property of interest with depth. We refer to these quantities as "lower mantle clusters".

In order to evaluate the models, as in Flament (2019), we compute the accuracy $A c c=(T P+T N) / A$ and sensitivity $S=T P /(T P+F N)$ to quantify the match between present-day lower mantle clusters from flow models and seven S-wave tomographic models: SAW24B16, Mégnin and Romanowicz (2000); HMSL-S, Houser et al. (2008); S362ANI,

280 Kustowski et al. (2008); GyPSuM-S, Simmons et al. (2010); S40RTS, Ritsema et al. (2011); SAVANI, Auer et al. (2014); and SEMUCB-WM1, French and Romanowicz (2014). TP stands for "true positives" indicating that a high-temperature cluster for mantle flow models and a low-velocity cluster for seismic tomographic models; similarly, TN ("true negatives") corresponds to a low-temperature cluster and a high-velocity cluster for flow models and seismic tomographic models, $F N$ ("false negatives") corresponds to low-temperature cluster and low-velocity cluster for flow models and seismic tomographic models, respectively, and $A$ is Earth's total surface area.

\section{Results}

\subsection{Implications of alternative reference frames}

We compare five different reconstructions between $200 \mathrm{Ma}$ and $900 \mathrm{Ma}$ to assess the consequences of alternative assumptions and approach for reference frame construction (Fig. 2), including a standard paleomagnetic reference frame

(Merdith et al., 2021) (PMAG), a no-net-rotation reference frame (NNR), our reference frame which is optimised with respect to tectonic rules (OPT), an orthoversion reference frame from Cao et al. (2021a) following Mitchell et al. (2012) (ORTHO) and a reference frame based on combination of paleomagnetic and geological data incorporating the alignment of plume products at the surface with fixed LLSVP edges (Torsvik and Cocks, 2019) (FIX_LLSVP). At 200 Ma (Fig. 2a) all reconstructions are quite similar, however, by $300 \mathrm{Ma}$ a visible difference is emerging between FIX_LLSVP and

all other reconstructions in terms of the longitudinal positions of continents. At this time, South America is located about $20^{\circ}$ farther westward in FIX_LLSVP compared with all other reconstructions, keeping in mind that there are only two tie points for a longitudinal correction based aligning plume products with the African LLSVP: the Skagerrak Central LIP and a Scandinavian kimberlite (Torsvik and Cocks, 2019). At 400 Ma the NNR, OPT and ORTHO reference frame are still very similar, but deviating substantially from both PMAG and FIX_LLSVP reference frames, in particular the longitudinal continental positions in the FIX_LLSVP frame, which ties kimberlites and LIPs in Siberia to the Pacific LLSVP (Torsvik and Cocks, 2019). This assumption requires the western edge of Laurussia (North America, Greenland and Baltica combined) to migrate $\sim 80^{\circ}$ westward back in time between $300 \mathrm{Ma}$ and $400 \mathrm{Ma}$ (Fig. 2a), translating to a 
speed of $\sim 9 \mathrm{~cm} / \mathrm{yr}$ of a large continental mass including several cratons and a small amount of ocean crust. This contracts with the analysis of Zahirovic et al. (2015) who found that the RMS speeds of plates with more than 50\% of their area comprised of continental crust predominantly have RMS speeds between $2 \mathrm{~cm} / \mathrm{yr}$ and $4 \mathrm{~cm} / \mathrm{yr}$. This reflects the substantial continental drag resisting plate motion in these cases, casting doubt on the viability of the FIX_LLSVP scenario. The differences between both OPT and NNR cases on the one hand with FIX_LLSVP on the other hand are even more extreme at 500 Ma. In FIX_LLSVP Laurentia (North America and Greenland) is aligned with the Pacific LLSVP, $45^{\circ}$ farther west than at $400 \mathrm{Ma}$ (Fig. 2a), while the longitudinal positions of Laurentia and Gondwana have not changed much in the OPT and NNR reconstructions, reflecting both the minimisation of net rotation as well as limits imposed on the speeds of continents in the OPT case. The PMAG reconstruction is quite different to all other models, as expected, as it is not a mantle reference frame and implies no constraints on longitude.

For times older than $500 \mathrm{Ma}$ (Fig. 2b) we only compare four reconstructions as the model by Torsvik and Cocks 315 (2019) does not reach back to $600 \mathrm{Ma}$. Firstly, there is distinctive similarity between the OPT and NNR reconstructions, even though the OPT case minimises trench migration speeds and penalises global continental velocities in addition to minimising net rotation. The primary reason for this is that trench migration and net rotation are relatively closely coupled, so minimising one also reduces the other to a large extent, and continents typically do not tend to move fast when both net rotation and trench migration is minimised, even if explicit constraints are not introduced for continents. This comparison provides an important insight, namely that the simple lithospheric no-net-rotation rule used to produce the NNR model produces results that are not dramatically different from a model optimised by a set of more general tectonic rules. This is important because NNR models have been frequently used in tectonic and mantle flow models for practical reasons (e.g., Mao and Zhong, 2021; Zhong and Rudolph, 2015; Behn et al., 2004; Kreemer and Holt, 2001) in the absence of other available mantle reference frames. Our results suggest here that NNR reference frames are not entirely unrealistic from a tectonic rules point of view. The PMAG model is expectedly quite different, with no longitudinal and plate speed constraints imposed, while the orthoversion model (ORTHO) is very different as well by design, as it follows the idea that Rodinia formed about $90^{\circ}$ east from Pangea, such that Pangea assembled over the western subduction girdle bounding Rodinia (Mitchell et al., 2012). Interestingly, our OPT reconstruction implies instead that Pangea formed about $90^{\circ}$ east of Rodinia. We stress that this model behaviour emerges naturally from our optimisation parameters without being imposed. It is important to note that Mitchell et al. (2012) found that their data could not discriminate well between one or the other scenario, i.e. Pangea either forming $90^{\circ}$ east or west of Rodina. They merely favoured a westward migration of the two successive supercontinent centres because they thought this solution would minimise plate speeds. Instead, our optimised reconstruction suggests that the opposite solution minimises plate velocities. In summary, an unexpected outcome of our optimised absolute reference frame is that it generates an orthoversion-consistent reconstruction by following a completely different approach from that used by Mitchell et al. (2012), thus independently lending support to the concept as a natural evolutionary pathway of successive supercontinents. 


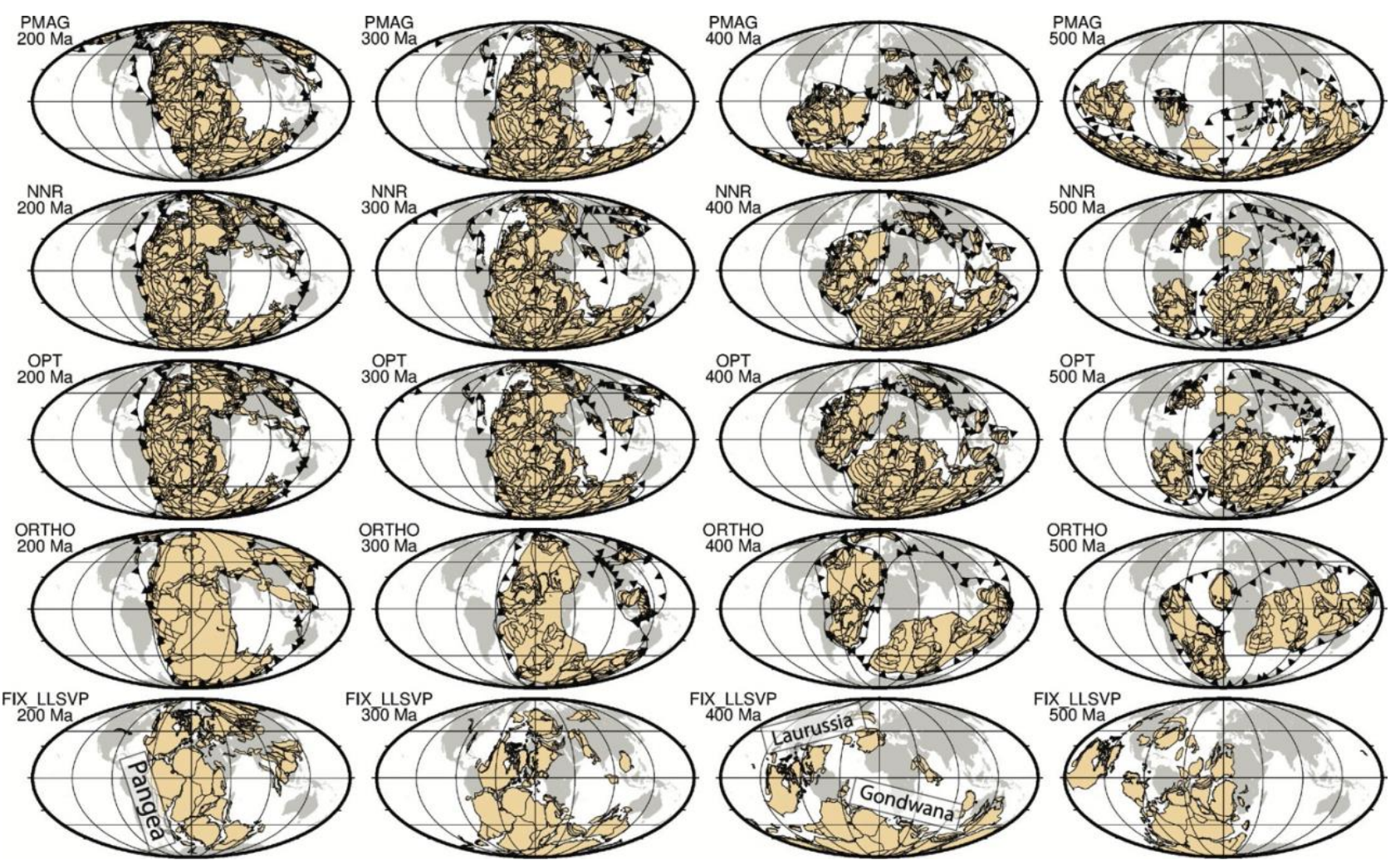

Figure 2. Plate reconstructions based on alternative approaches for modelling absolute plate motions, with reference frames based on paleomagnetic data (PMAG) (Merdith et al., 2021), No-Net-lithospheric-Rotation (NNR), tectonic rulesbased optimisation (OPT), orthoversion from Cao et al. (2021a) following Mitchell et al. (2012) and a combination of paleomagnetic data with aligning LIPs with the edges of LLSVPs assumed to be stationary (Torsvik and Cocks, 2019), covering the time period from 200-900 Ma. The reconstruction of Torsvik and Cocks (2019) does not extend back to $600 \mathrm{Ma}$ and older. Continents are outlined in beige while subduction zones are toothed black lines. The present-day position of continents is shown in light grey in the background as a reference. 

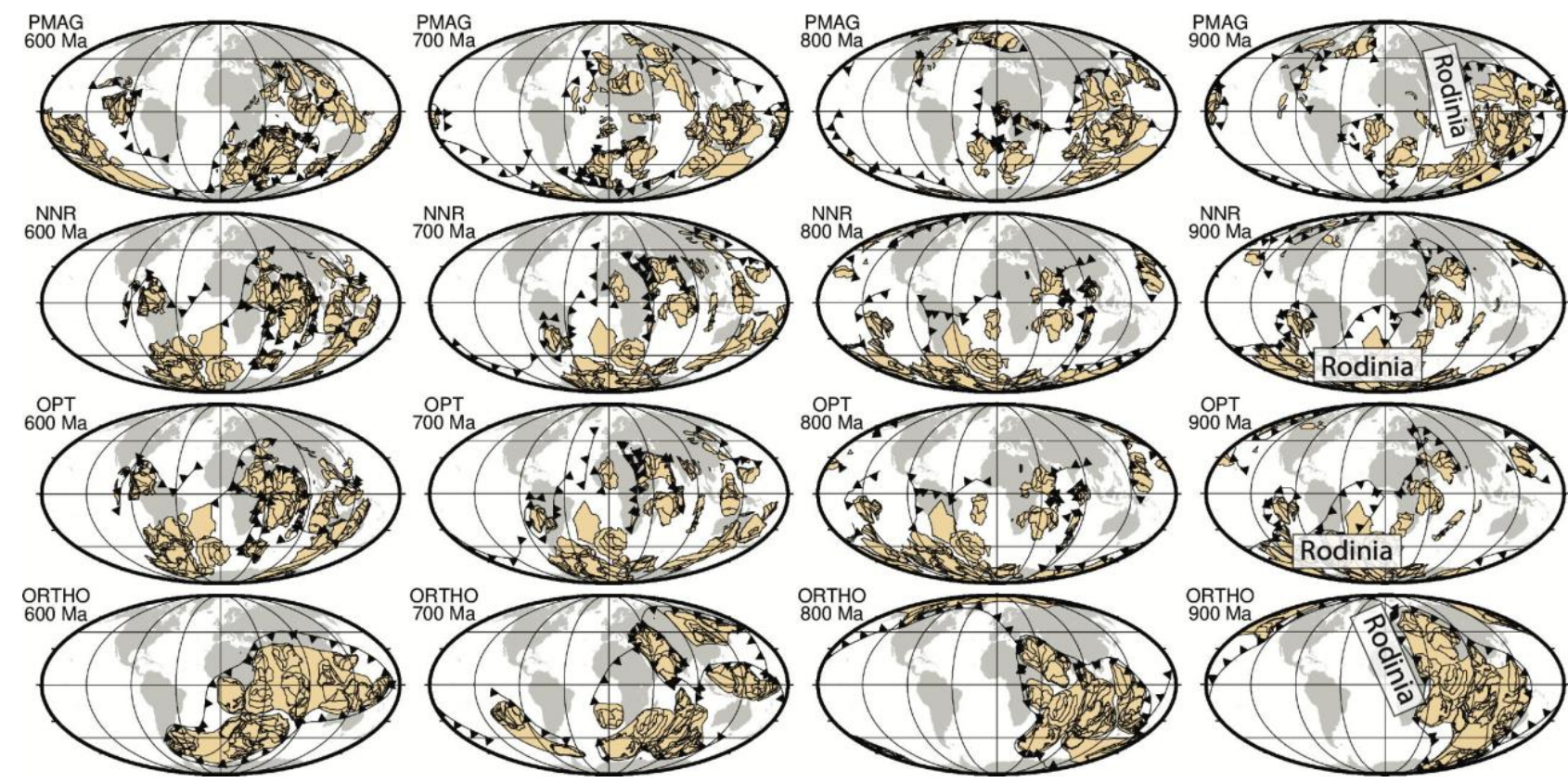

Figure 2 (continued)

\subsection{Lithospheric net rotation}

The dramatic reduction of lithospheric net rotation in our optimised reference frame relative to the PMAG reference frame is illustrated in Figure 3a, which compares net rotation of our optimised model with the paleomagnetic reference frame from Merdith et al. (2021) and the mantle reference frame model by Matthews et al. (2016) incorporating the Paleozoic reconstruction from Domeier and Torsvik (2014), with the latter being similar to the model of Torsvik and Cocks (2019) shown on Figure 2. These two Paleozoic models (Domeier and Torsvik, 2014; Torsvik and Cocks, 2019) are constructed as mantle reference frames, by following the idea that by applying a TPW correction and aligning LIPs and kimberlites with the edges of LLSVPs an approximation of the "true" latitude and longitude of plates relative to the mantle is obtained. If this were the case, we would expect to see the large fluctuations in lithospheric net rotation seen in a model based on paleomagnetic data alone (Fig. 3b) dramatically reduced. However, the result of applying empirical

360 TPW and longitudinal corrections as proposed by Domeier and Torsvik (2014) results in $0.4^{\circ}-1.5^{\circ} / \mathrm{Myr}$ of net lithospheric rotation, which is up to five times larger than the rates regarded as reasonable based on geodynamic considerations (Becker, 2006; Conrad and Behn, 2010) (Fig. 3b). This simple test demonstrates that the absolute plate motion corrections introduced by Domeier and Torsvik (2014) do not in fact produce a reasonable mantle reference frame. In contrast, if absolute plate motions are jointly optimised for minimising net rotation, trench migration and fast continent velocity, we obtain a model that displays net rotation with rates less than $0.25^{\circ} / \mathrm{Myr}$. 

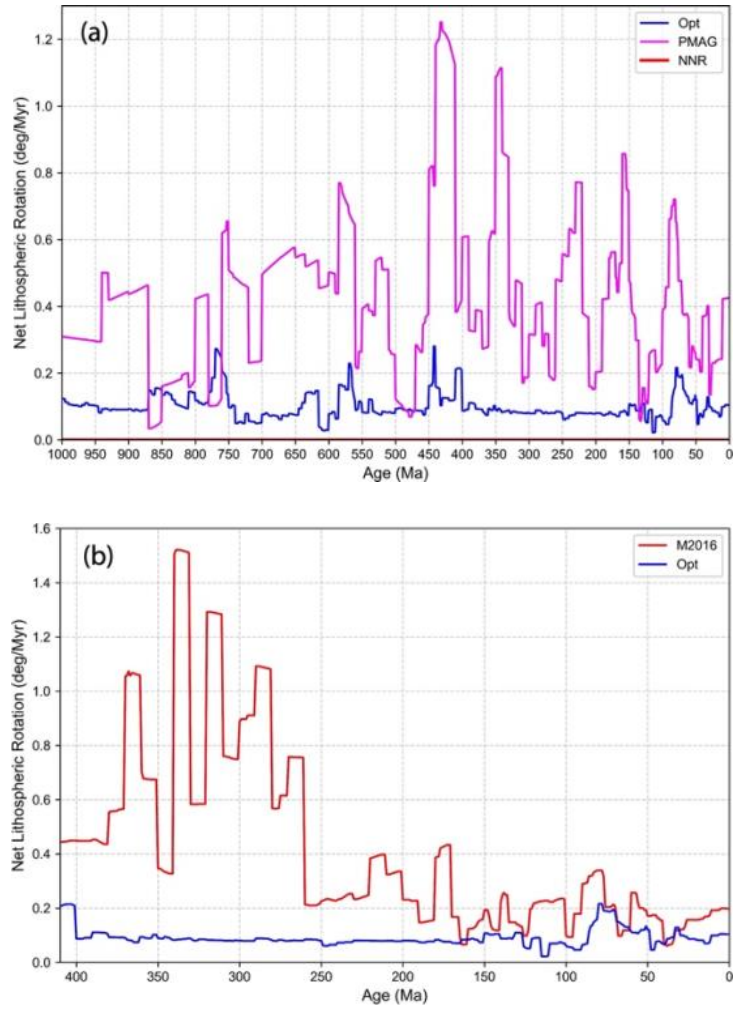

Figure 3. (a) Net lithospheric rotation of the paleomagnetic reference frame from Merdith et al. (2021) (PMAG, magenta)

versus our optimised reference frame (OPT, blue) with weights for $\mathrm{NR}=1$ (net rotation), $\mathrm{TM}=0.5$ (trench migration), and $\mathrm{PV}=0.5$ (absolute plate velocity of continental regions) from $1000 \mathrm{Ma}$ to the present with the NNR model shown for reference in red with zero net rotation. For the period of 80-0 Ma hotspot tracks are used in addition as part of the optimisation, with a weight $\mathrm{HS}=1$ (fitting of present-day hotspots to age-progressive seamount tracks). Net rotation is below $0.25 \% \mathrm{Myr}$, as recommended by independent geodynamic studies (Conrad and Behn, 2010; Becker, 2006). (b) Net rotation of the mantle reference frame model by Matthews et al. (2016) which is based on a combination of the models by Müller et al. (2016) from 230-0 Ma and Domeier and Torsvik (2014) for the period of 410-250 Ma, compared to our optimised model. The Domeier and Torsvik (2014) model is similar to the model by Torsvik and Cocks (2019) (Fig. 2), but the latter does not include plate topologies, and can therefore not be used to compute net rotation.

\subsection{Subduction zone migration}

Compared to the paleomagnetic model (Fig. 4a), our optimised model (Fig. 4b) exhibits significantly reduced trench-orthogonal subduction zone migration scatter as well as reduced median absolute deviation of trench motion (Fig. 5), reflecting the suppression of fast, geodynamically unreasonable global trench migration rates. The substantial overall 
improvement in the scatter of trench migration velocities is expressed in limiting the bulk of trench advance to a relatively narrow band of rates to $0-3 \mathrm{~cm} / \mathrm{yr}$ (Figs $4 \mathrm{a}, \mathrm{b}$ ). Subduction zone retreat exhibits more scatter, particularly between 150 Ma and $100 \mathrm{Ma}$ and before $190 \mathrm{Ma}$, but the majority of retreating trench speeds are confined to $0-4 \mathrm{~cm} / \mathrm{yr}$ for most of the model. In addition, the optimised model exhibits a notable improvement over the no-net-rotation model (Fig. 4c) in confining the majority of trench advance to $0-2 \mathrm{~cm} /$ year and the majority of trench retreat to $0-4 \mathrm{~cm} / \mathrm{year}(\mathrm{c})$. There are periods during which the scatter of trench migration speeds is systematically smaller or larger than those observed during Pangea stability and after Pangea breakup (Fig. 4b). In the last 320 million years the Median Absolute Deviation (MAD) of subduction zone migration is largely between $-1 \mathrm{~cm} / \mathrm{yr}$ (trench advance) and $2 \mathrm{~cm} / \mathrm{yr}$ (trench retreat), with the exception of the Early Cretaceous period with a MAD of up to $4 \mathrm{~cm} / \mathrm{yr}$ (Fig. 5). During periods of Rodinia amalgamation (prior to $940 \mathrm{Ma}$ ) and stability (940-870 Ma) the MAD of trench migration is confined to $-1 /+2 \mathrm{~cm} / \mathrm{yr}$, while Pangea assembly/stability from $320 \mathrm{Ma}$ to $\sim 200 \mathrm{Ma}$ is characterised by a range of $-2 /+2 \mathrm{~cm} / \mathrm{yr}$ (Fig. 5). The relative subduction zone stability during these periods reflects that during the late stage of closure of internal ocean basins that are consumed in the process of supercontinent amalgamation, subduction zone migration slows, and during phases of stability of a large continental mass the ring of subduction zones surrounding it is also relatively stable.

The opposite holds for times of supercontinental dispersal, during which the ring of subduction zones surrounding a supercontinent rolls back oceanward, accommodating the creation of new internal ocean basins. The spread of trench migration during the dispersal of Rodinia ( $~ 870-650 \mathrm{Ma})$ is in the range of $-2 /+5 \mathrm{~cm} / \mathrm{yr}$ (MAD, Fig. 5), slightly larger than that observed during the last $200 \mathrm{Ma}$, but the difference may simply be an artefact of much larger uncertainties for Neoproterozoic plate reconstructions. The period that stands out by displaying by far the largest scatter of trench migration, with the bulk between $-3 /+6 \mathrm{~cm} / \mathrm{yr}$, with some even larger outliers is the period from $600 \mathrm{Ma}$ to $320 \mathrm{Ma}$ (Fig.

405 5). This period stands out as the most dynamic time in terms of subduction zone migration in the last billion years and comprises most of the Paleozoic era with the exception of the Late Carboniferous and Permian. This is the antithesis of the "boring billion" (Brasier, 2012) - we propose to call it the "zippy tricentenary era", in short the "zippy tricentenary". Multiple internal ocean basins were destroyed in the process of the formation of Gondwana between $600 \mathrm{Ma}$ and $550 \mathrm{Ma}$, while after $490 \mathrm{Ma}$ the ephemeral Iapetus Ocean was replaced by the Rheic Ocean, separating several arc terranes from northern Gondwana. 
https://doi.org/10.5194/se-2021-154

Preprint. Discussion started: 26 January 2022

(c) Author(s) 2022. CC BY 4.0 License.
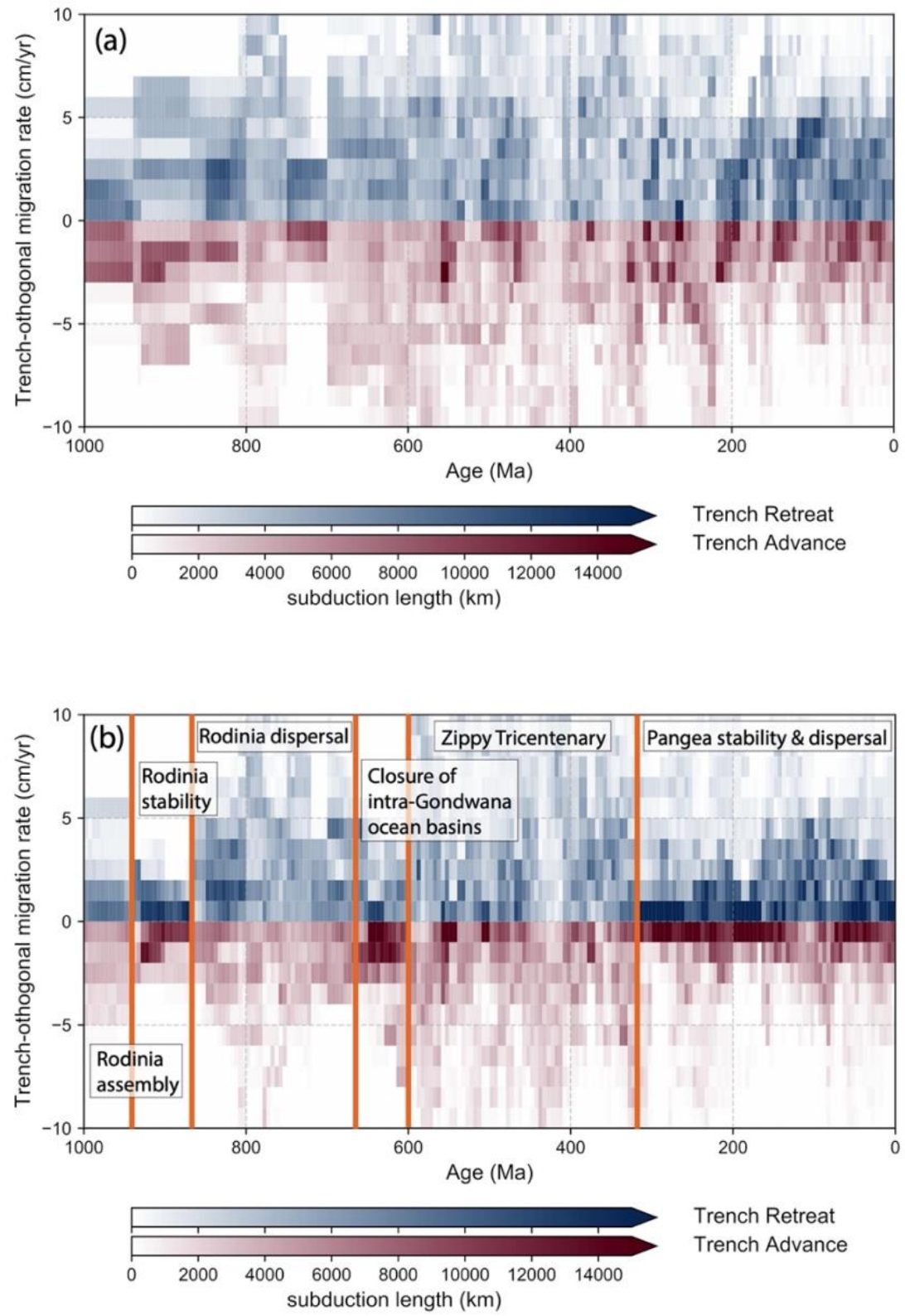

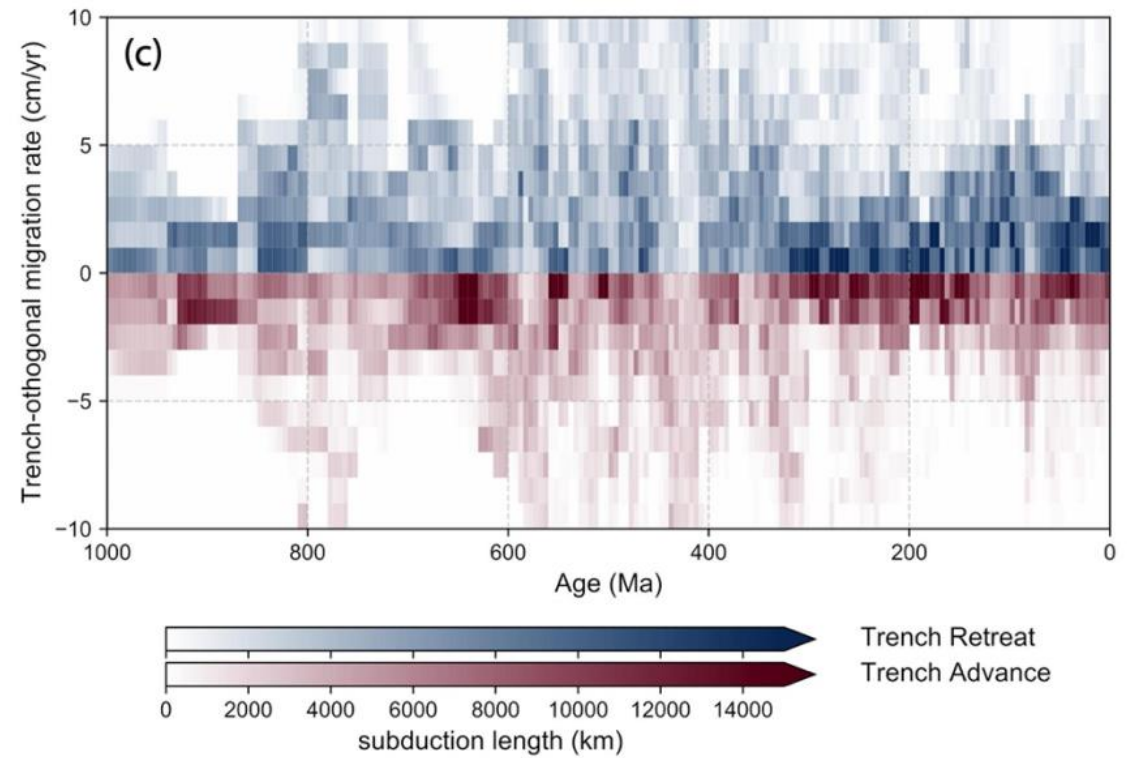

Trench Retreat

Trench Advance

Figure 4. Histogram of the trench-orthogonal overriding plate speed for (a) the plate motion model from Merdith et al. (2021), (b) the same model with net lithospheric rotation removed and (c) our optimized mantle reference frame. Colours are proportional to the length of subduction zones which are either retreating (blue) versus advancing (red) at a given rate. Both the no-net-rotation and optimised models limit the occurrence of unreasonably fast trench retreat or advance.

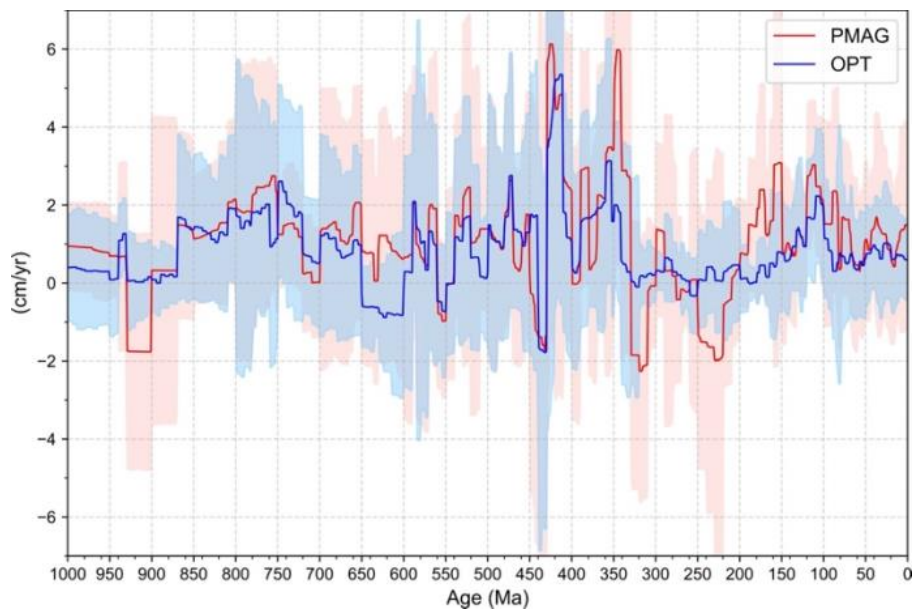

Figure 5. Median trench motion speed with median absolute deviation error range for the unoptimized plate motion model in red and the optimised model in blue, using a 5 Myr moving average window. Periods of supercontinent stability are characterised by very slowly moving subduction zones, but Rodinia dispersal and the following long period of the successive opening and closing of a number of internal ocean basins resulted in a larger prevalence of relatively fast subduction zone migration compared with Pangea dispersal. See text for discussion. 


\subsection{Continental and plate speeds}

The third parameter we use to impose tectonic rules on our optimised plate motion model is global continental RMS speeds. The paleomagnetic reference model (Fig. 6a) is characterised by plate and continental speeds that are frequently $50 \%$ or more above those of the optimized model (Fig. 6b), which both limits maximum continental RMS speeds below the continental "speed limit" of $10 \mathrm{~cm} / \mathrm{yr}$ (Zahirovic et al., 2015) whilst minimizing peaks in plate speeds. The short-lived peak in plate speeds at 590-570 Ma is likely related to an artefact in the reconstruction of now subducted ocean basins.
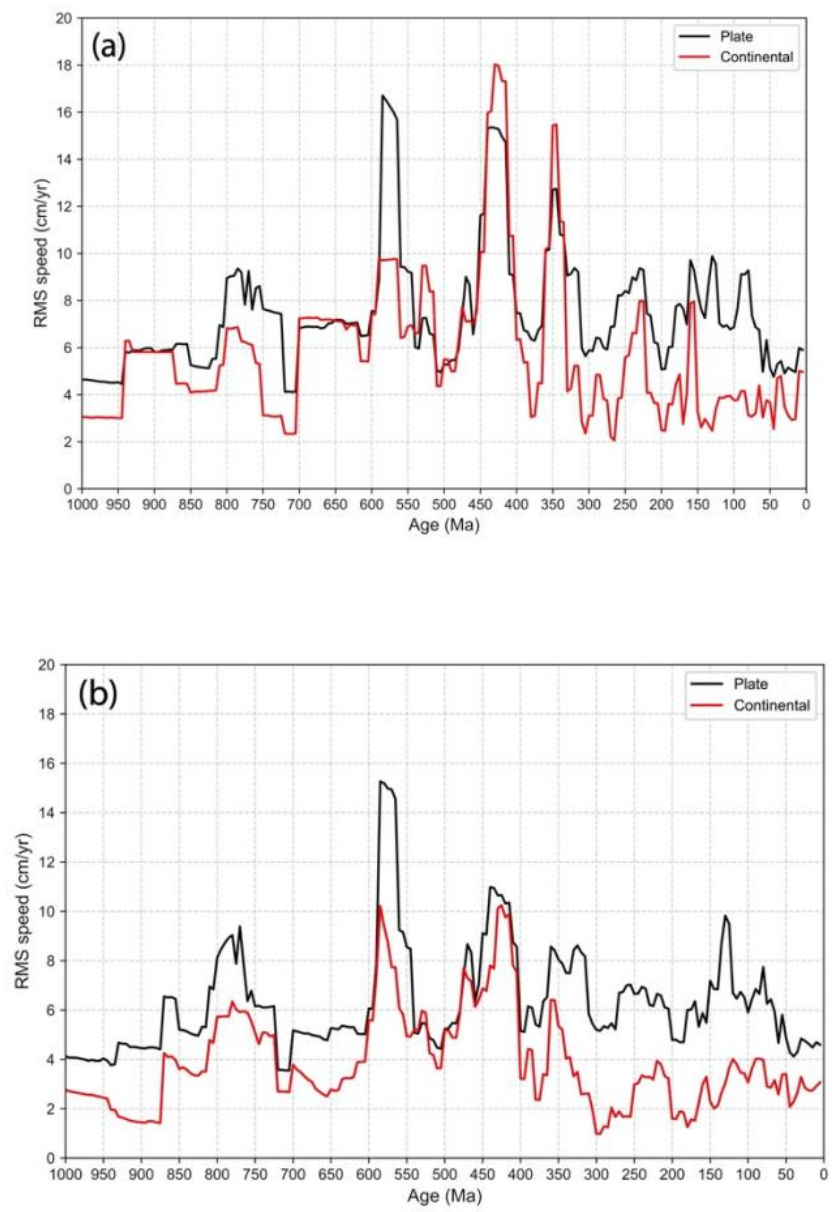

Figure 6. Root mean square (RMS) speeds of all plates and continents in the paleomagnetic model (a), and the optimised model (b). The paleomagnetic model displays large RMS speeds of plates and continents up to $18 \mathrm{~cm} / \mathrm{year}$. The no-netrotation model alleviates outliers to a large extent, with the optimised model especially reducing mean continental speeds 
further. Some time periods, notably 600-550 Ma and 450-400 Ma, still show relatively large RMS speeds, likely reflecting artefacts in the reconstruction of relative plate motions and plate boundaries.

\subsection{Mantle flow models}

Our mantle flow models are driven by imposed surface plate velocities, subduction zone locations and geometries (Supp. Animation S1) and reconstructed age-area distributions of the ocean crust through time (Figs 7, 8, Supp. Animation S2), following the method of Williams et al. (2021). The predicted evolution of mantle temperature primarily records the effect of changing subduction zone topologies and convergence velocities and the age of subducting slabs through time. Here we focus on the evolution of basal mantle structure (Figs 9 and 10), particularly relevant for understanding the history of deep mantle plumes, and on the upper mantle structure through time (Fig. 10) which is connected with surface magmatism via upper mantle temperature anomalies and upwellings. To do this, we compare output from two mantle flow models, OPT1 (Fig. 9a) and OPT2 (Fig. 9b), which differ in buoyancy ratio for the basal mantle layer (Table 1) (see also Supp. Animations S3-S10). Model outputs for the NNR and PMAG models are included in the supplementary material (Figs S1-S4, S6 and S7). We use virtual transparent globes displaying the modelled timedependent mantle temperature structure to visualise the response of the 3D geometry of the basal layer and associated upwellings to the evolving geometry and volume of slabs descending in the mantle (Fig. 12). The development of basal mantle structures in response to subduction in our model is illustrated in two views of the mantle through time: One view is centred at $270^{\circ} \mathrm{E}$, a meridian crossing the centre of Rodinia in the south and the Mirovoi Ocean in the north at $800 \mathrm{Ma}$ while straddling the eastern Pacific Ocean at present-day (Fig. 12a) while a second view is centred at $150^{\circ} \mathrm{E}$, straddling subduction zones bounding the eastern portion of Rodinia in the south and crossing the boundary between India and the Mirovoi Ocean in the north (Figs 8, 12b and Supp. Animation S11). 


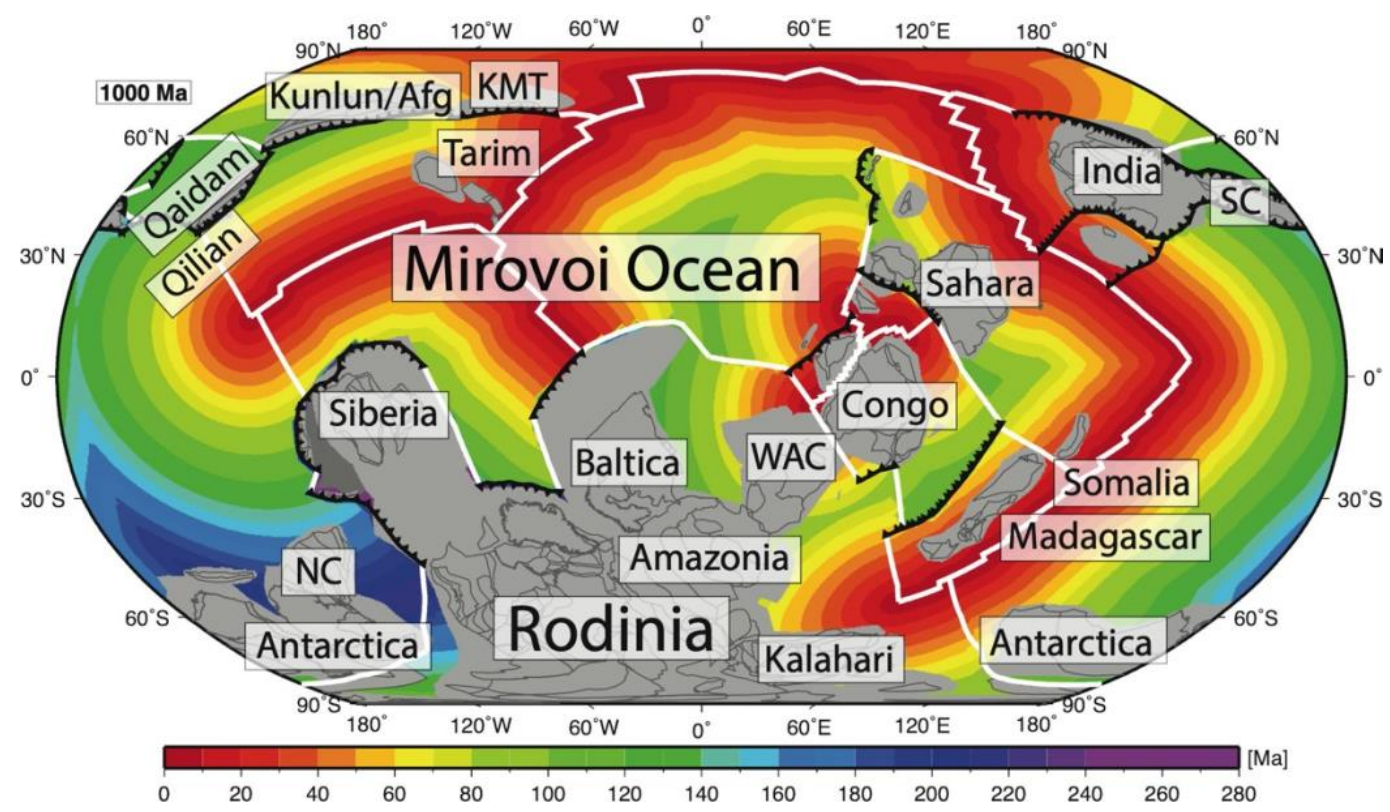

Figure 7. Reconstruction at $1 \mathrm{Ga}$ with synthetic age of the ocean floor reconstructed using the method by Williams et al.

465 (2021) with mid-ocean ridges shown as white lines, subduction zones as toothed black lines, regions of continental crust filled with grey and individual continental blocks are labelled; Afg = Afghanistan, KMT = Krygyz Middle Tianshan, SC $=$ South China, $\mathrm{NC}=$ North China, WAC $=$ West Africa Craton.

During the first 400 million years of model evolution (1000-600 Ma) the basal mantle structure is dissected into a network of ridges and nodes as a response to a widely dispersed network of subduction zones from 1000-760 Ma, preventing any extensive basal mantle structure akin to present-day LLSVPs to form (Fig. 9a). Between 760 Ma and 560 $\mathrm{Ma}$, an equatorially-centred subduction girdle forms in our model, restricted to a latitude range less than $60^{\circ}$ (Fig. 8a), accompanied by an arrangement of the continents within the same latitudinal belt. This gives rise to the formation of two coherent, extensive polar basal mantle structures, connected by a small number of evolving, ephemeral basal ridges, which persist to $500 \mathrm{Ma}$ (Fig. 9a). The subsequent movement of Gondwana, some fragments of Eurasia and associated subduction zones to higher latitudes starts dissecting the previously formed polar basal mantle structures while a coherent Pacific basal structure emerges around $400 \mathrm{Ma}$ (Fig. 8a). As no subduction zones migrate into this region after $400 \mathrm{Ma}$, the structure consolidates itself over the next 200 million years, without any equivalent on the opposite, African side forming, reflective of the persistent subduction zones between Gondwana and Laurussia (Fig. 9). A coherent sub-African basal mantle structure only starts emerging in our model about 20-40 million years after the breakup of Pangea, reflecting the time involved in the effect of sinking slabs on the lowermost mantle structure to fade away after cessation of subduction between Gondwana and North America after $380 \mathrm{Ma}$ (Figs 9a, 10). 
https://doi.org/10.5194/se-2021-154

Preprint. Discussion started: 26 January 2022

(C) Author(s) 2022. CC BY 4.0 License.

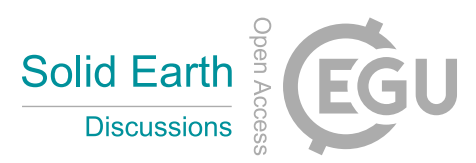

(c) (i)

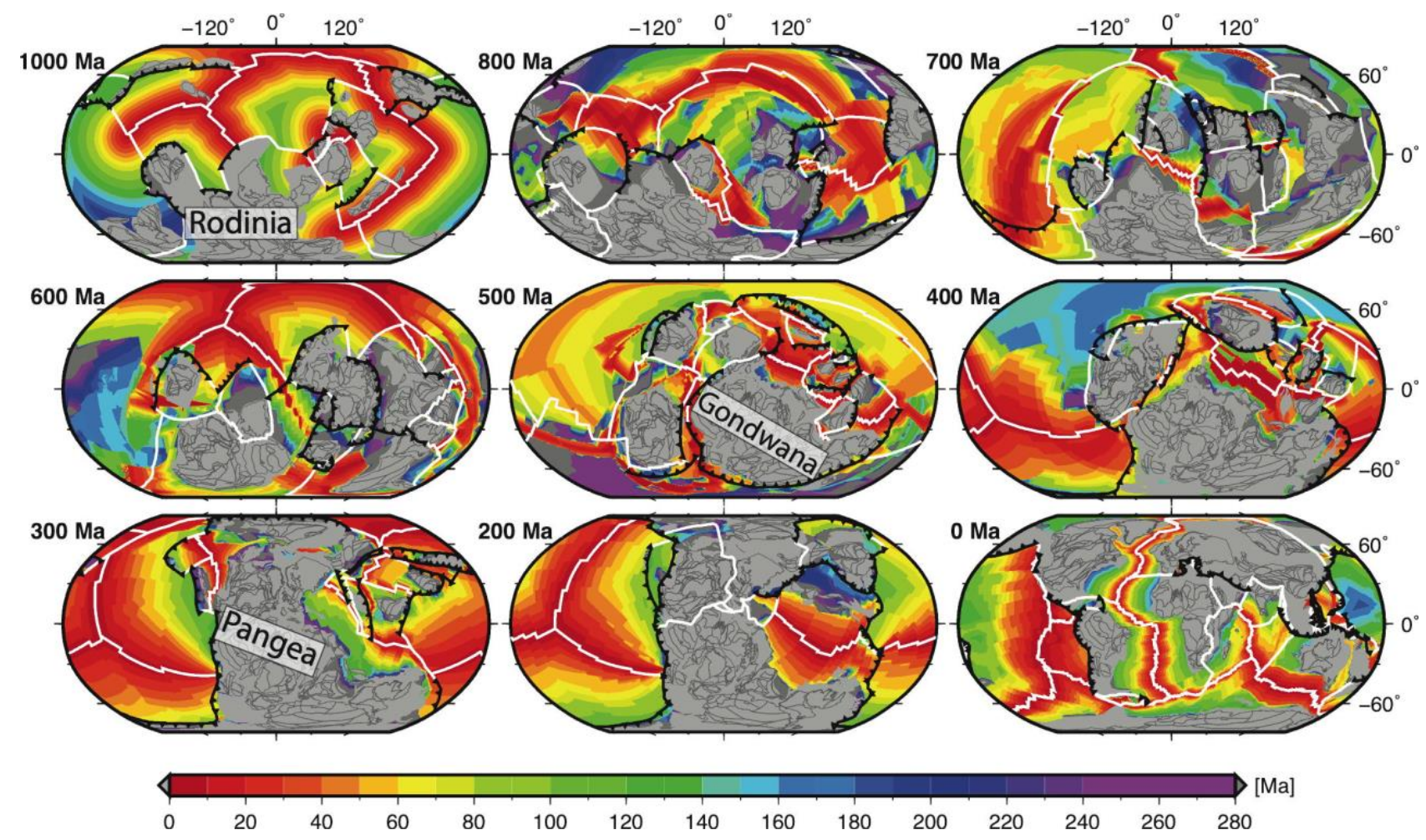

Figure 8. Oceanic crustal age grids from $1 \mathrm{Ga}$ to the present constructed from plate rotations and boundaries in $100 \mathrm{Myr}$

intervals following Williams et al. (2021), with plate boundaries and continents coloured as in Fig. 7.

These results are consistent with the inference from Cao et al. (2021a) that it may take 160-240 Myr for the basal mantle structure to reflect changes in subduction zone geometry at the surface. Our model thus records five distinct intervals of mantle convection geometry: (1) a network of dissected basal ridges and nodes (1000-600 Ma), (2) a short-

lived degree-2 basal mantle structure centred on the north and south pole (600-500 Ma), (3) a transitional state in which the north polar basal structure migrates southward and gradually morphs into a Pacific-centred structure while the south polar structure is dissected by subducting slabs and disintegrates into a network of ridges and nodes (500-400 Ma), (4) a Pacific-centred degree-1 structure (400-200 Ma) and (5) a degree-2 structure akin to what is observed today (160-0 Ma) which is composed of a long-lived Pacific basal structure joined by an African counterpart which gradually amalgamates during a $\sim 40 \mathrm{Myr}$ transition after the breakup of Pangea at $200 \mathrm{Ma}$. The overall evolution described above is similar for models OPT1 (Figs 9a, 10a) and OPT2 (Figs 9b and 10b), demonstrating that the excess density of the basal mantle layer plays a secondary role, in comparison to the imposed plate motion history, in driving large-scale mantle structure through time (Figs 9a and b, Supp Figs S1-S4, Supp. Animations S3-S6). 
https://doi.org/10.5194/se-2021-154

Preprint. Discussion started: 26 January 2022

(c) Author(s) 2022. CC BY 4.0 License.

(c) (1)

500
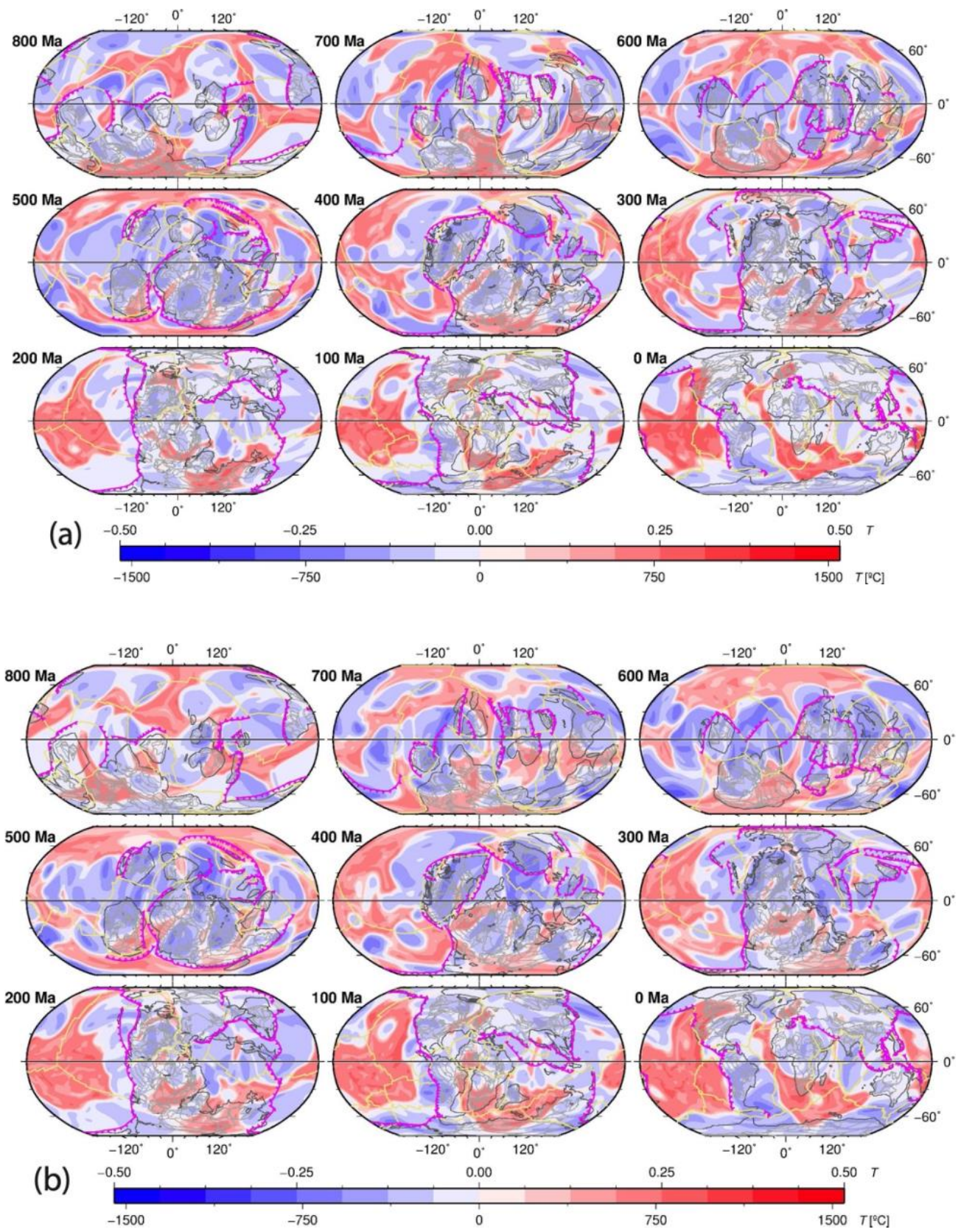

Figure 9. Map view of mantle temperature anomalies relative to the mean temperature at $2677 \mathrm{~km}$ depth for our geodynamic reference model OPT1 (a) and model OPT2 (b) from $800 \mathrm{Ma}$ to the present (see Table 1 for model parameters). Reconstructed present-day coastlines and continental sutures are shown as thin grey lines, while outlines of continents are displayed as bold grey lines. Subduction zones are bold magenta lines with triangles pointing towards overriding plates while mid-ocean ridges are shown as yellow lines. The black line along the equator highlights the location of the mantle cross-sections shown in Figure 8. 
https://doi.org/10.5194/se-2021-154

Preprint. Discussion started: 26 January 2022

(c) Author(s) 2022. CC BY 4.0 License.

(c) (1)

510

Upper mantle temperature anomaly maps at $400 \mathrm{~km}$ depth (Fig. 11, Figs S5-S7) complement the view of the lower mantle evolution of our model and allows us to evaluate the mantle temperature response to the history of subduction as well as upwellings underneath continents, which is of interest as some continental magmatism may be partly driven by upper mantle temperature anomalies (as well as compositional anomalies but these are not modelled

515 here). These maps show individual deep mantle plumes intersecting this depth as bright red dots (Fig. 11) and highlight time periods during which continental regions overrode subducting slabs, leading to cooler than average upper mantle temperatures in these regions, while at the same time potentially enriching the mantle transition zone in these regions with volatiles from subducting slabs (e.g. Mather et al., 2020; Safonova et al., 2015; Cao et al., 2021c). This is observed under Siberia, Baltica and North America between 420-380 Ma, under North America between 100-40 Ma and along the rim of eastern/southern Asia and Zealandia after 100 Ma (Fig. 11) (see also Supp. Animations S7-S10). 
https://doi.org/10.5194/se-2021-154

Preprint. Discussion started: 26 January 2022

(c) Author(s) 2022. CC BY 4.0 License.

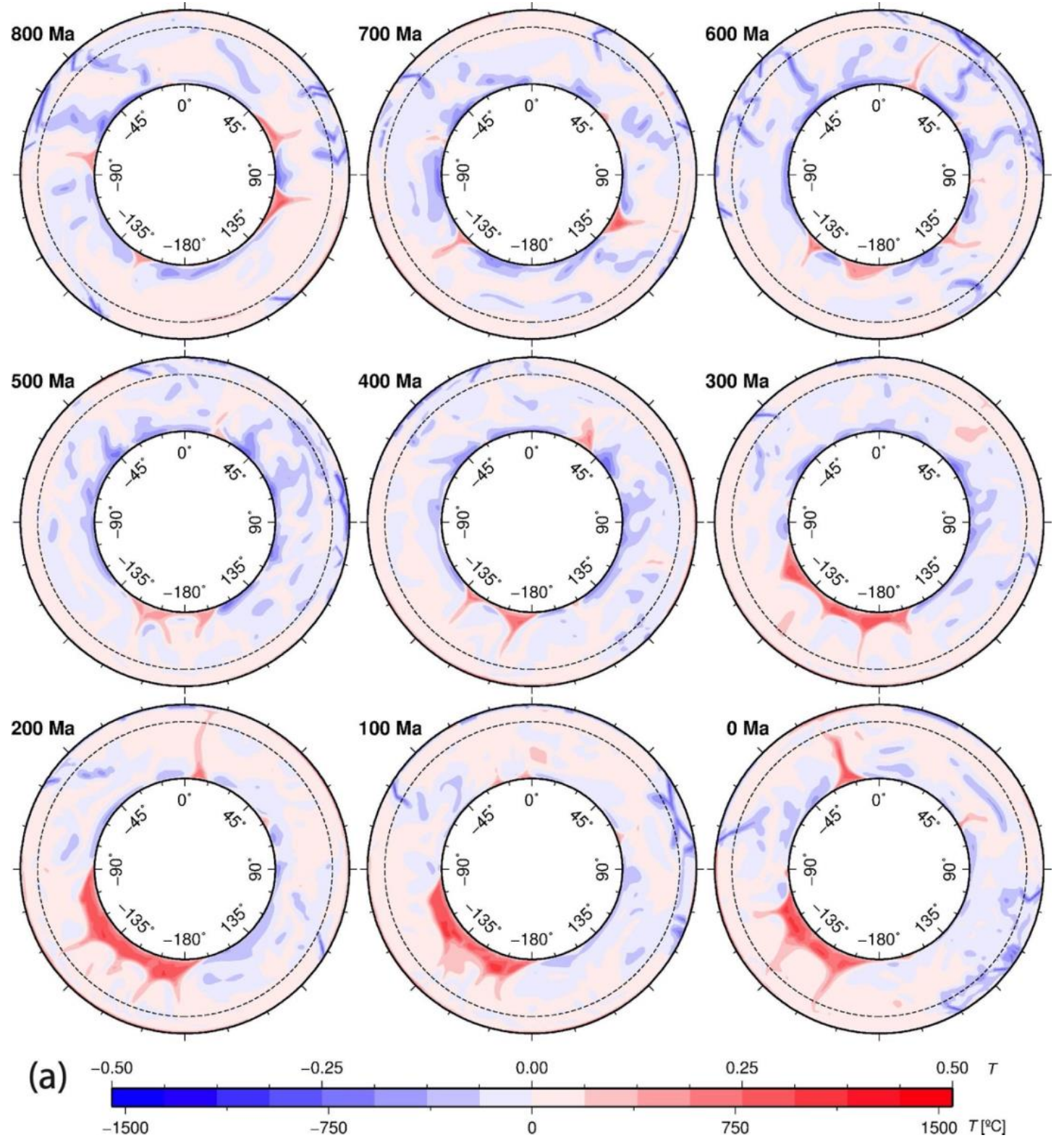


https://doi.org/10.5194/se-2021-154

Preprint. Discussion started: 26 January 2022

(c) Author(s) 2022. CC BY 4.0 License.
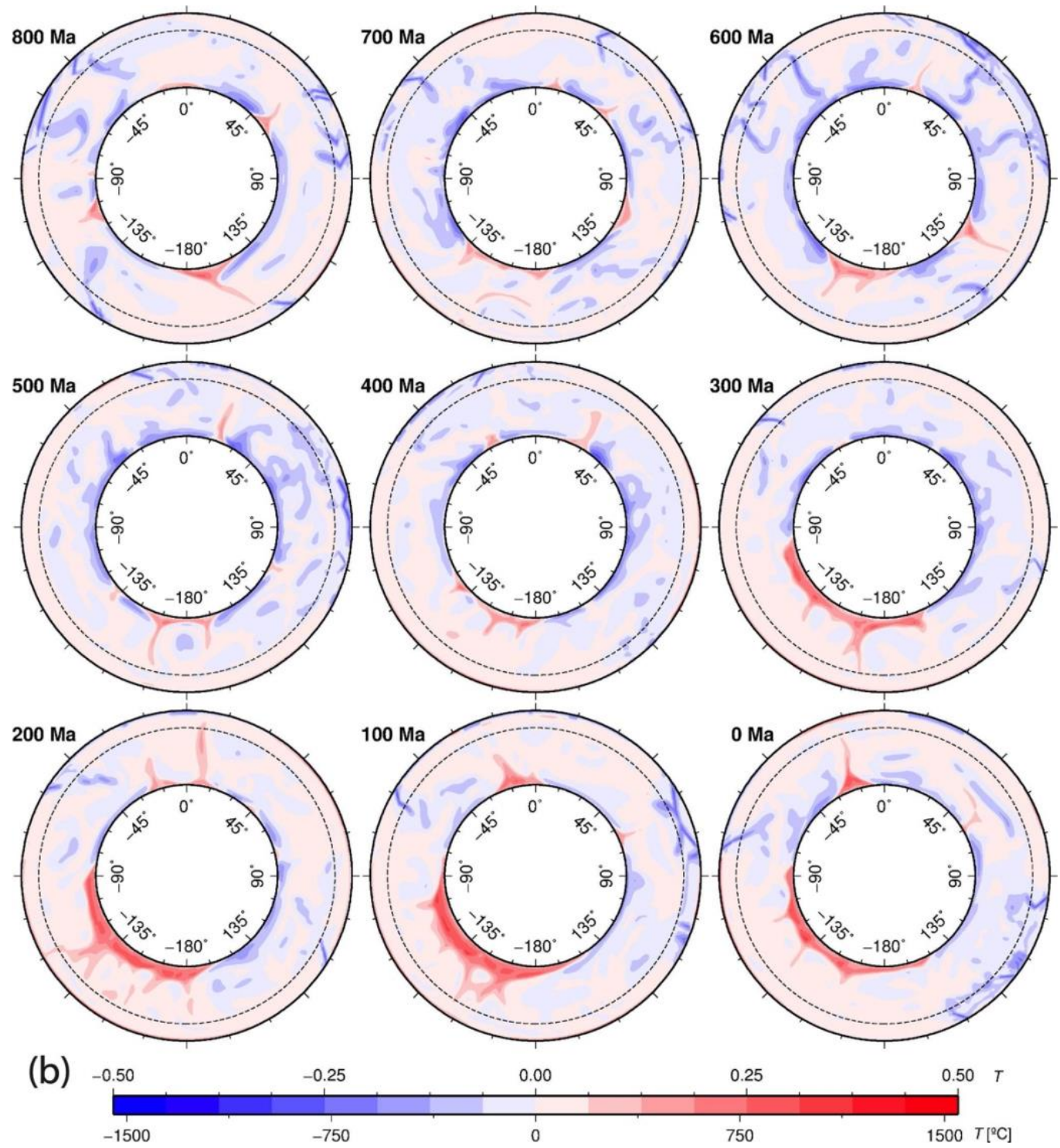

Figure 10. Global equatorial mantle cross-sections for our geodynamic reference model OPT1 (a) and OPT2 (b), distinguished by a difference in the excess density of the basal mantle material (see Table 1) in 100 Myr increments since $800 \mathrm{Ma}$. The dashed black line is the boundary between the upper and lower mantle. Numbers above the colour palette represent non-dimensional temperature anomalies, while numbers below the colour palette are dimensional temperature anomalies. 
https://doi.org/10.5194/se-2021-154

Preprint. Discussion started: 26 January 2022

(c) Author(s) 2022. CC BY 4.0 License.

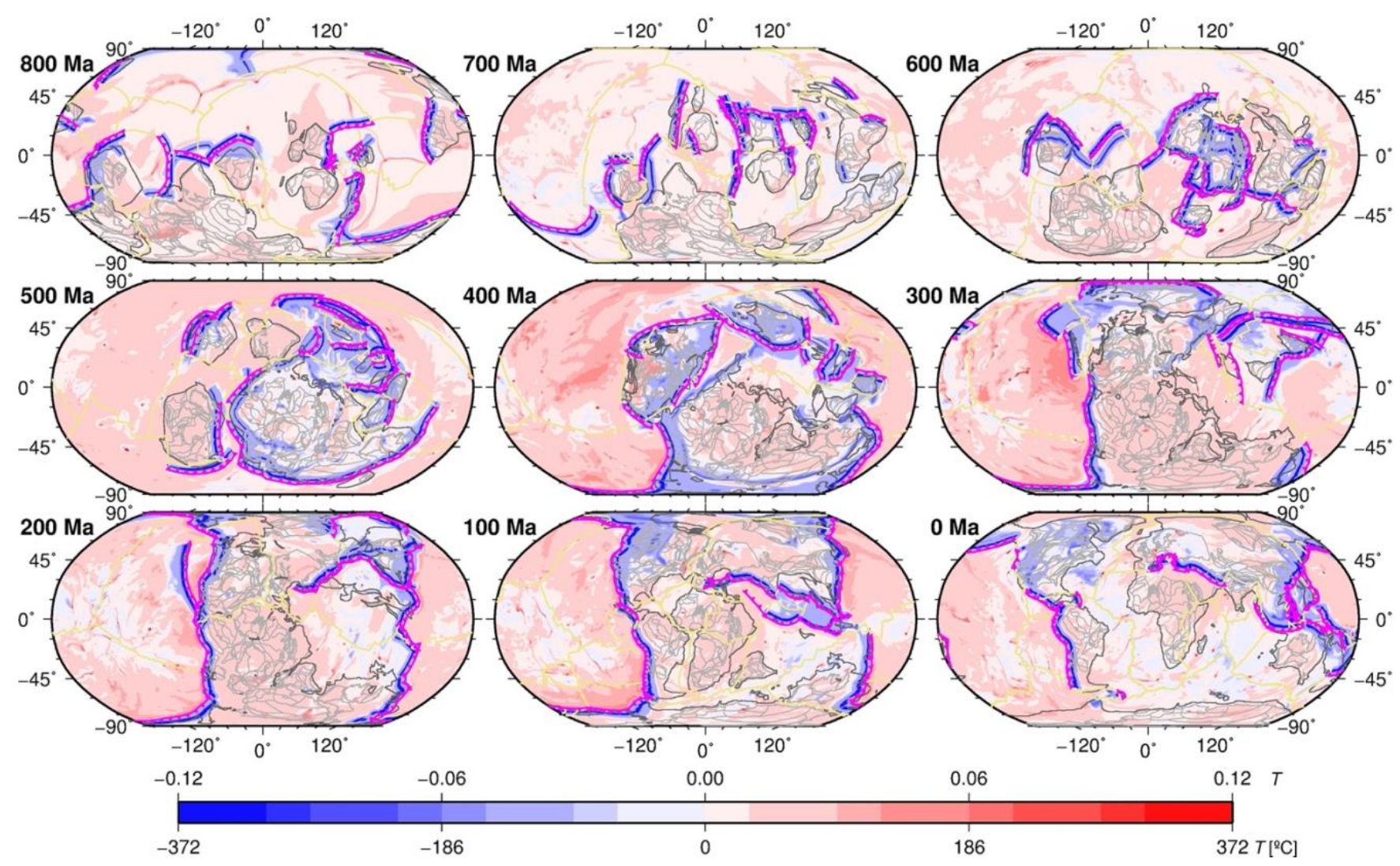

Figure 11. Map view of mantle temperature anomalies relative to the mean temperature at $396 \mathrm{~km}$ depth for our

540 geodynamic reference model OPT1 in $100 \mathrm{Myr}$ increments since $800 \mathrm{Ma}$. Reconstructed present-day coastlines and continental sutures are shown as thin grey lines, while outlines of continents are displayed as bold grey lines. Subduction zones are bold magenta lines with triangles pointing towards overriding plates while mid-ocean ridges are shown as yellow lines.

\section{3.6 Cluster analysis of modelled versus tomographically imaged mantle structure}

The spatial match between modelled lower mantle temperature clusters between 1,000 km and 2,800 km depth at present-day from models OPT1 and OPT2 versus seismic tomographic clusters from tomographic models GypsumS, HMSL.S, s40RTS, S3662ANI, SAVANI, saw24b16 and SEMUCB-WM1d (Auer et al., 2014; French and Romanowicz, 2014; Houser et al., 2008; Kustowski et al., 2008; Mégnin and Romanowicz, 2000; Ritsema et al., 2011; Simmons et al., 2010) is illustrated in Figure 13. The relatively larger basal mantle structure buoyancy ratio in model OPT2 relative to our reference model OPT1 results in a larger lateral extent of lower mantle structures (Figs 12a, b). In particular, the 
anomalously hot lower mantle cluster centered on the Pacific extends significantly beyond the anomalously slow structures captured in the tomography models (Fig. 13b), while the anomalously hot structure underneath Africa is also more extensive in OPT2 than in OPT1. In this instance, the spatial extent of this structure as imaged in the tomography models is somewhat underestimated in OPT1 (Fig. 13a), highlighting the difficulty of finding a model that matches equally well in all regions.

The model accuracy, i.e. the fraction of correct predictions of all our mantle flow models in terms of the clusters analysed here, is best as compared to tomographic models SAVANI (Auer et al., 2014) and HMSL-S (Houser et al., 2008) at $~ 75-76 \%$, followed by S40RTS (Ritsema et al., 2011) not far behind at 73-74\% (Fig. 14a). GyPSuM-S (Simmons et al., 2010) represents an outlier at the low end with an accuracy of 58-62\% because the seismically-slow cluster covers a larger area in this tomographic model (Fig. 12). GyPSuM-S is different from the other tomographic models used here as it includes constraints from geodynamic and mineral physics (Simmons et al., 2010).

In contrast to the model accuracy, sensitivity is the true positive rate at which the mantle flow model reproduces the geographical distribution of slow clusters in tomographic models, i.e. it represents the percentage of anomalously slow mantle from tomographic models that is correctly matched by modelled hot mantle temperature anomalies (Fig. 14b). Model sensitivity covers a range of 52-65\%, differentiating our preferred model OPT1 clearly from all other models (Fig. 13b). The OPT1 sensitivity is larger than $61 \%$ for all tomographic models with the exception of S362ANI 570 (Kustowski et al., 2008) and SAW24B16 (Mégnin and Romanowicz, 2000). In terms of sensitivity, the paleomagnetic and no-net-rotation mantle flow models are the most lowly ranked models with a mean of 56-57\% averaged across all seven tomographic models. The top three tomographic models in terms of their match to mantle flow model OPT1 are SEMUCB-WM1 (French and Romanowicz, 2014), SAVANI (Auer et al., 2014) and S40RTS (Ritsema et al., 2011), with a sensitivity between 64 and 66\%. In summary, our preferred mantle flow model OPT1 produces the highest mean for accuracy (72\%) and sensitivity (61\%) averaged across all seven tomographic models while SAVANI (Auer et al., 2014) and S40RTS (Ritsema et al., 2011) consistently produce high scores for models OPT1 and OPT2 for both accuracy and sensitivity (Figs 14a, b). 
https://doi.org/10.5194/se-2021-154

Preprint. Discussion started: 26 January 2022

(c) Author(s) 2022. CC BY 4.0 License.

(a)

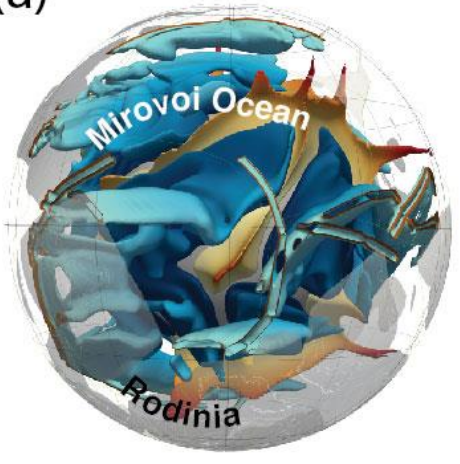

$500 \mathrm{Ma}$
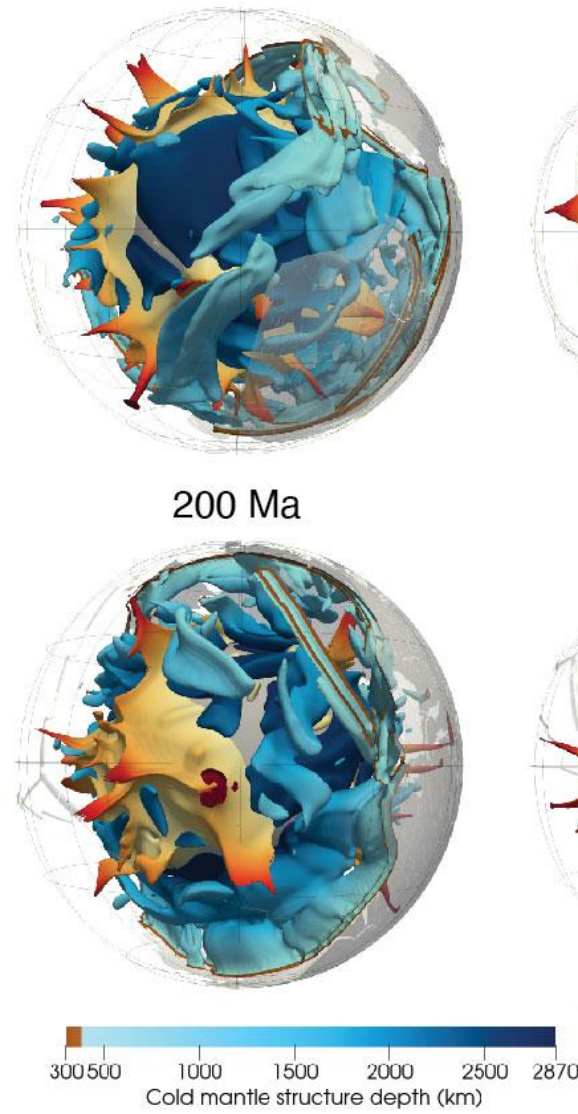

$700 \mathrm{Ma}$

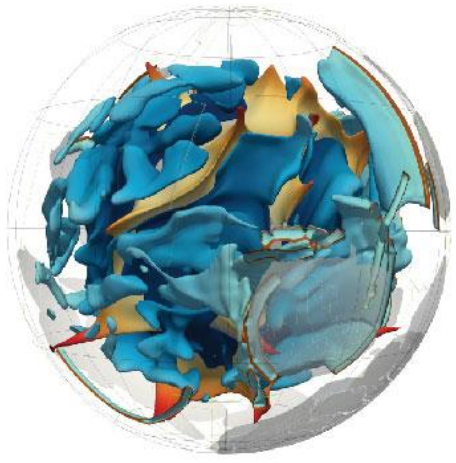

$400 \mathrm{Ma}$

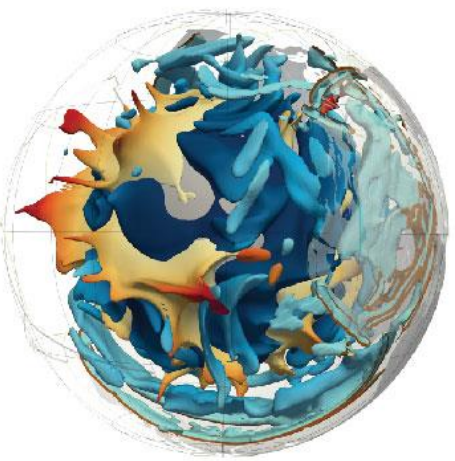

$100 \mathrm{Ma}$

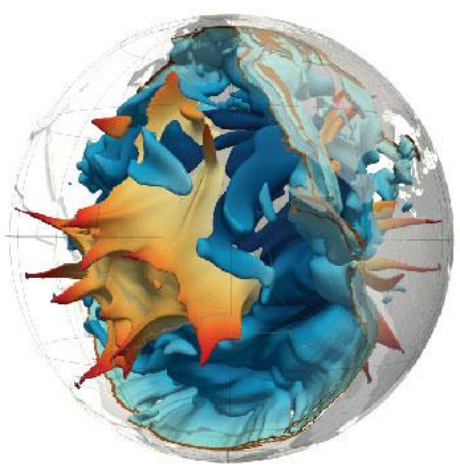

$600 \mathrm{Ma}$

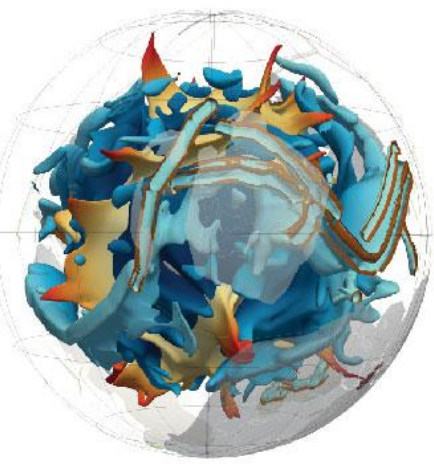

$300 \mathrm{Ma}$

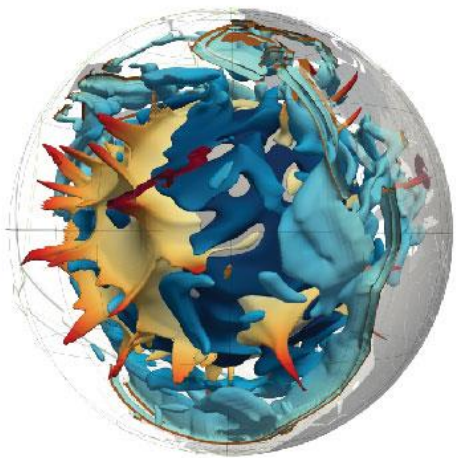

Present-Day

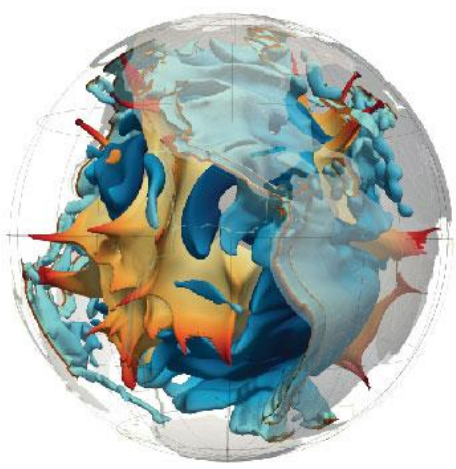

$\begin{array}{cccccc}170500 \quad 1000 \quad 1500 & 2000 & 2500 & 2870 \\ \text { Hot mantle structure depth } & (\mathrm{km}) & \end{array}$ 

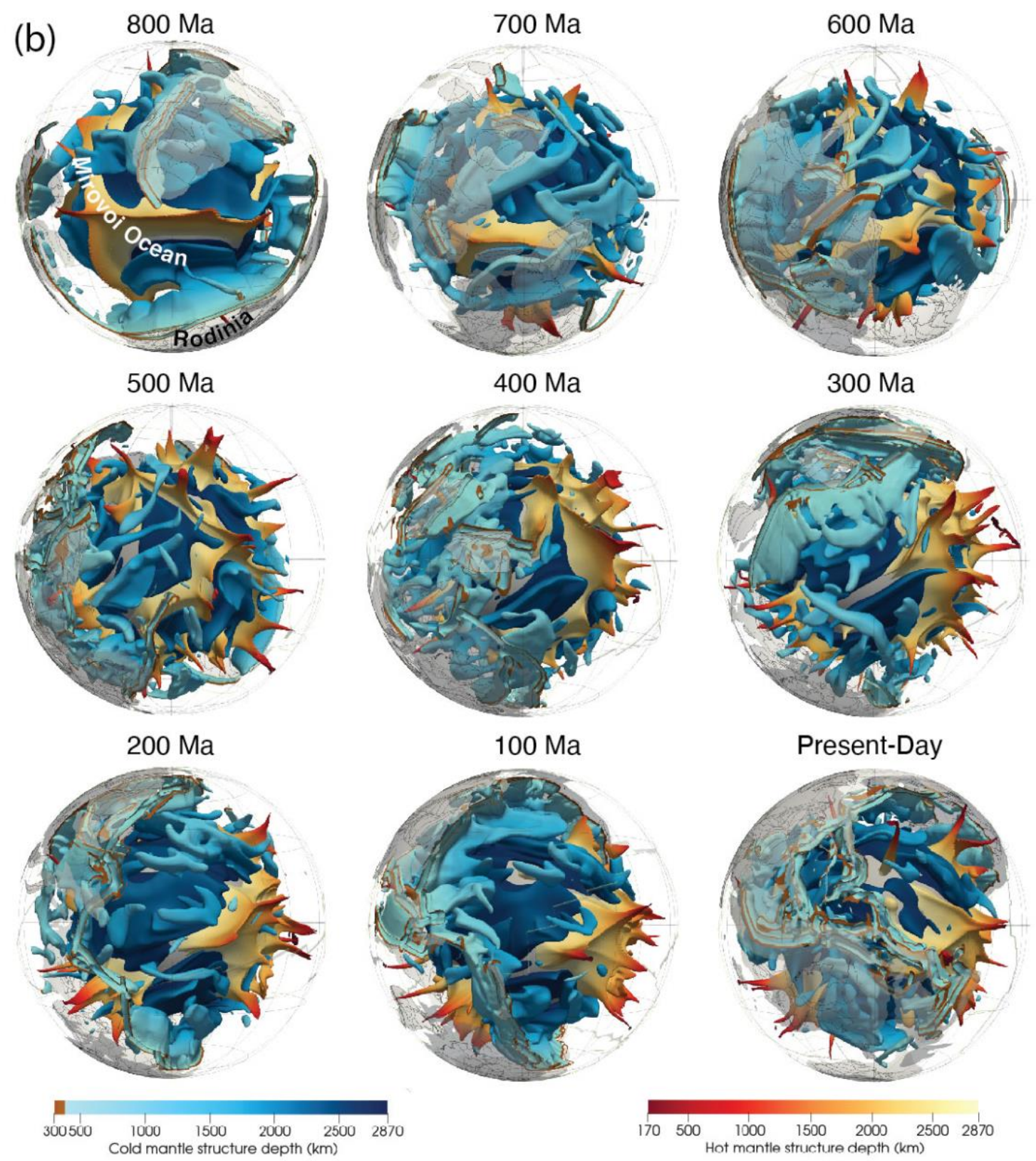

Figure 12. Visualisation of modelled mantle structure through time focussing on the Pacific hemisphere since $800 \mathrm{Ma}$ in $100 \mathrm{Myr}$ intervals with central meridians at $270^{\circ} \mathrm{E}$ (a) and $150^{\circ} \mathrm{E}$ (b). Mantle hotter than the layer average by nondimensional value $0.1(305 \mathrm{~K})$ is shown in orange while mantle colder than the layer average by non-dimensional value $-0.05(153 \mathrm{~K})$ is shown in blue, highlighting anomalously hot and cold mantle structures, largely corresponding to upwellings and subducting slabs, respectively. 
(a)
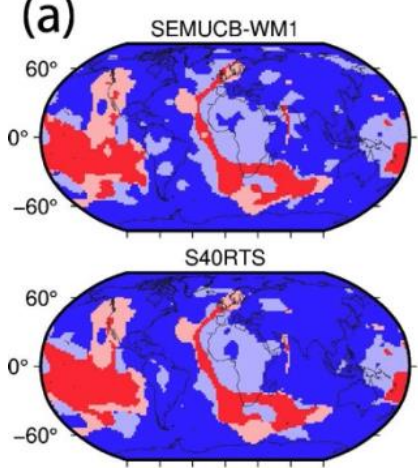

S362ANI

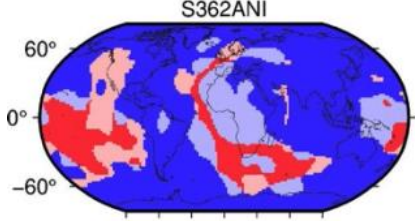

SAW24B16

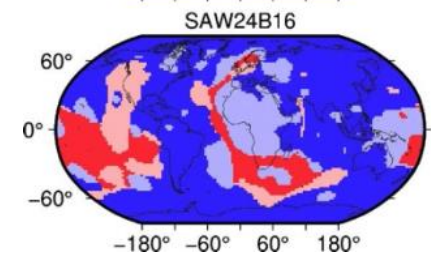

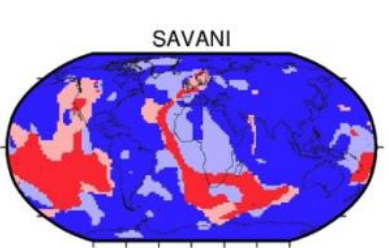

GYPSUMS

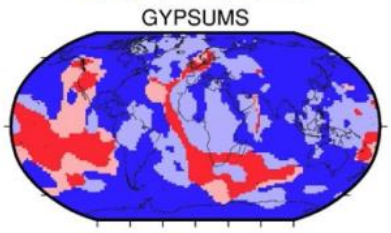

HMSL-S
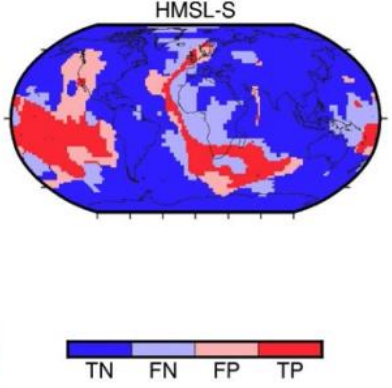
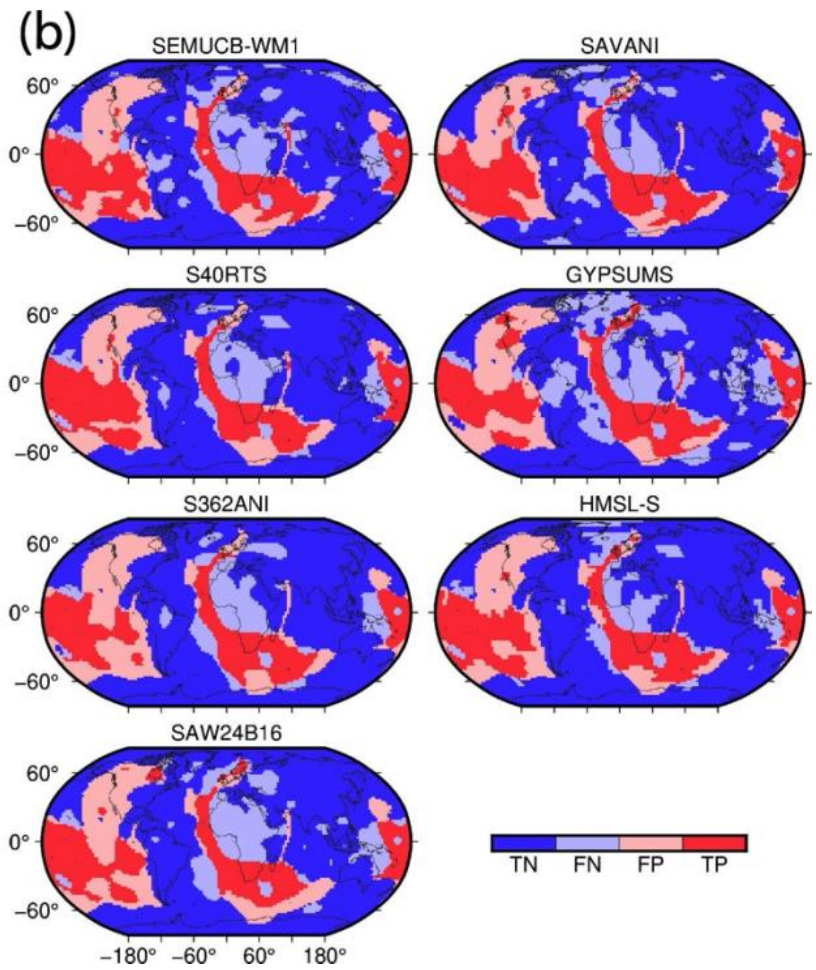

Figure 13. Spatial match between modelled lower mantle temperature clusters between $1,000 \mathrm{~km}$ and 2,800 km depth at present-day from models OPT1 (a) and OPT2 (b) versus seismic tomographic clusters from tomographic models SAW24B16, Mégnin and Romanowicz (2000); HMSL-S, Houser et al. (2008); S362ANI, Kustowski et al. (2008);

GyPSuM-S, Simmons et al. (2010); S40RTS, Ritsema et al. (2011); SAVANI, Auer et al. (2014); and SEMUCB-WM1, French and Romanowicz (2014). Dark red indicates true positive areas for hot/slow mantle while dark blue indicates true negative regions for cold/fast mantle and grey indicates true negative areas. Light red indicates false positives, i.e. hightemperature mantle clusters paired with low-velocity regions, while light blue indicates false negatives, i.e. lowtemperature mantle clusters paired with low-velocity mantle regions. Coastlines are shown in black. TN=True Negative, $\mathrm{FN}=$ False Negative, $\mathrm{FP}=$ False Positive and $\mathrm{TP}=$ True Positive. 

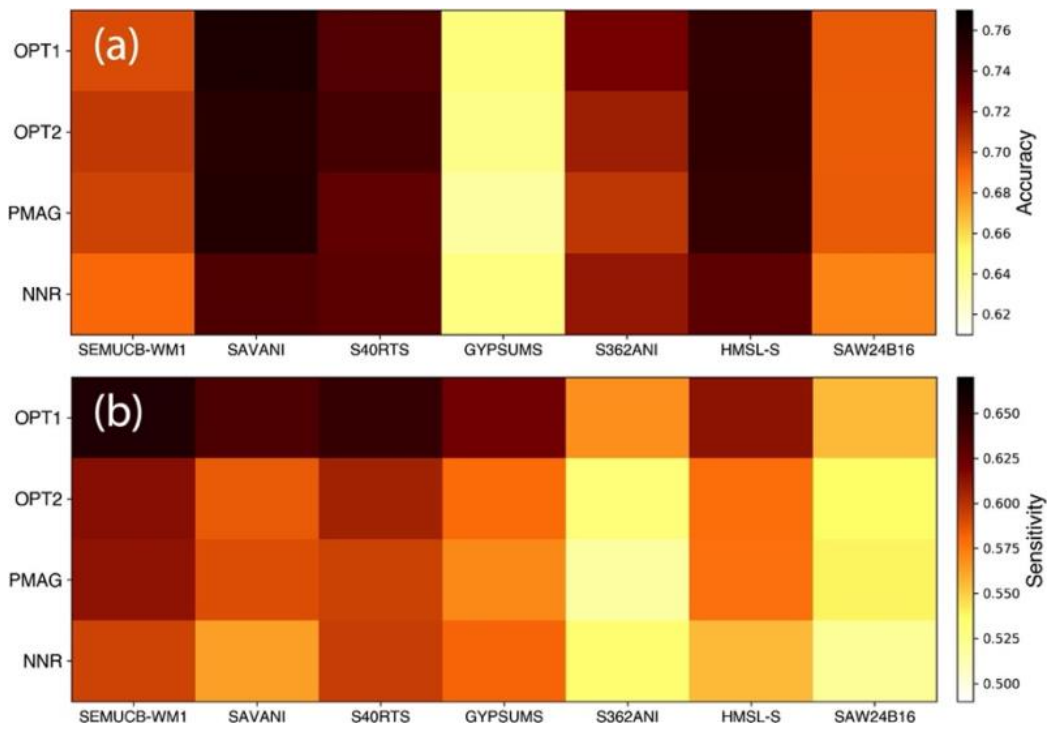

Figure 14. Quantitative match between predicted lower mantle temperature clusters between 1,000 and 2,800 km depth of our four mantle flow models OPT1, OPT2, PMAG and NNR at present-day and seven seismic tomographic clusters

615 from models GypsumS, HMSL.S, s40RTS, S3662ANI, SAVANI, saw24b16 and SEMUCB-WM1 shown as model accuracy (a) and sensitivity (b).

\section{Discussion}

\subsection{Tectonic rules-based mantle reference frame implications}

Our tectonic rules-based absolute plate motion model in a mantle reference frame provides an alternative methodology to constrain both latitudes and longitudes of plates and continents through time. Our optimised model lacks the distinct northward migration of Pangea during and after its assembly featured in the model by Merdith et al. (2021) (compare reconstructions at $400 \mathrm{Ma}$ and $300 \mathrm{Ma}$ on Fig. 2a). This $60^{\circ}$ migration, confined mostly to 400-250 Ma, is present in many Pangea reconstructions and was attributed to true polar wander by Le Pichon et al. (2021), an interpretation confirmed by our reconstruction, considering that the migration is absent in our mantle reference frame which does not consider true polar wander. The similarity between our optimised and NNR models confirms that an NNR tectonic reference frame is a reasonable approximation for use in mantle convection models. 
In terms of subduction zone migration, our results suggest that the distribution of trench migration, largely confined to a relatively narrow range of $\pm 2 \mathrm{~cm} / \mathrm{yr}$ during the assembly of Pangea and during its breakup and dispersal 630 (Fig. 5), does not hold for pre-Pangea times, apart from stability during assembly of Rodinia (1000-870 Ma) during the assembly of Gondwana (650-600 Ma). For other times before the assembly of Pangea, the spread of subduction zone migration rates was significantly larger (Fig. 5), particularly during the period from 600 Ma to 320 Ma (Fig. 4), the "zippy tricentenary", when multiple internal ocean basins evolved, closed and opened rapidly (Fig. 2), coinciding with a peak in passive margin length (Sobolev and Brown, 2019). The beginning of this period follows on closely from the conclusion of the Boring Billion and the end of Neoproterozoic 'snowball' Earth glaciations (Hoffman and Schrag, 2002). The "zippy tricentenary" might have been initiated by a major burst in surface erosion and subduction zone lubrication event (Sobolev and Brown, 2019), coming to an end when this lubrication became depleted. The "zippy tricentenary" coincides with a global sea level high and a minimum of land area (Kocsis and Scotese, 2021), driven partly by increased oceanic crustal production and an associated increase in the proportion of young, shallow seafloor (Fig. 8).

After the assembly of Gondwana a number of new ocean basins formed around its periphery, separating it from Laurentia, Baltica, Siberia and other blocks now part of Asia, successively creating and destroying ocean basins including the Iapetus Ocean (Fig. 8). The period was characterised by numerous relatively short subduction zones, which have the capacity to roll back faster than long subduction zones (Schellart et al., 2008). After 490 Ma the ephemeral Iapetus ocean was replaced by the Rheic Ocean, separating several arc terranes from northern Gondwana, also characterised by fast trench migration of relatively short subduction zones. Ultimately the difference in the spread of trench migration behaviour (shown as its median absolute deviation in Fig. 5) between the Paleozoic "zippy tricentenary" as compared to the relatively sluggish Late Mesozoic/Cenozoic dispersal of Pangea, reflect that the latter was characterised by a smaller number of relatively long subduction zones which cannot roll back easily, as shown by mantle flow models (Schellart et al., 2007). The rollback potential of subduction zones wider than $4000 \mathrm{~km}$ is limited by the lacking ability of their central portions to migrate (Schellart et al., 2007). In contrast much of the Paleozoic Era was characterised by a profusion of relatively short subduction zones in the Merdith et al. (2021) reconstructions, many associated with rapidly evolving internal ocean basins (Fig. 6b).

The most surprising outcome of our mantle reference frame optimisation using a set of tectonic rules is that the resulting absolute plate rotations produce an orthoversion model in which the centres of Rodinia and Pangea are approximately offset from each other by $90^{\circ}$ in longitude (Fig. 2). However, this offset is in opposite direction to that proposed by Mitchell et al. (2012) - they favoured an offset between Rodinia and Pangea to the west to minimise plate velocities, but added that their model does not constrain the sense of motion well. In our model which minimises plate velocities, Pangea forms about $90^{\circ}$ to the east of Rodinia. The longitudinal sense of motion, constrained by our model, 
adds an important dimension to the Rodinia-Pangea orthoversion evolution, as knowing the longitudinal motion of the plates, and particularly the continents, between successive supercontinents, makes it possible to make geodynamic predictions about plate-mantle interaction, including the effect of dynamic topography and associated relative sea level change affecting the continents involved (e.g. Cao et al. (2019).

665

In our model Rodinia is located father south (mostly south of $60^{\circ} \mathrm{S}$ ), as compared to the model by Merdith et al. (2021) (Fig. 2). This difference may primarily reflect true polar wander, which our model is agnostic of since it is designed reconstruct plate locations relative to the mantle, without considering whole solid Earth rotations relative to its spin axis. In contrast, the Merdith et al. (2021) model includes motions of plates relative to the mantle as well as true polar wander.

670 Earth's true polar wander history includes a major episode of "Rodinia true polar wander" roughly from 800 Ma to 400 Ma (Mitchell, 2014). This corresponds to the main period during which the latitude and orientation of plates in our model diverges significantly from that of Merdith et al. (2021), providing a plausible explanation for the difference in the reference frames. This inference remains to be tested with independently computed true polar wander models for this time interval.

\subsection{Coupled plate-mantle evolution}

Similarly to previous models, our mantle flow model shows that the geometry and location of basal mantle structures is controlled by subducting slabs (e.g., Bunge et al., 1998; Garnero and Mcnamara, 2008; Zhong and Rudolph, 2015). Zhong et al. (2007) proposed that the evolution of subduction across supercontinent cycles may cause alternations between degree-1 and degree-2 planform convection. In contrast, Cao et al. (2021a), using simplified plate motion models to test alternative absolute reference frames since $1 \mathrm{Ga}$, including an orthoversion and no-net-rotation model, could not find evidence for degree-1 mantle convection to form in their models. Our mantle flow model, which differs from that used in Cao et al. (2021a) in that we use the plate motion model by Merdith et al. (2021) and a novel mantle reference frame, does demonstrate the development of a degree-1 planform, but as a relatively rare occurrence over the last $1 \mathrm{Gyr}$ (Fig. 9a). In our model, a Pacific-centred degree-1 basal structure forms in the leadup to the assembly of Pangea around $400 \mathrm{Ma}$ (Figs 8, 9), underneath a long-lasting superocean, with the underlying mantle largely protected from descending slabs after $\sim 600 \mathrm{Ma}$ (Figs 9, 10, 12). It takes approximately 200 million years for the basal Pacific mantle region to reflect the absence of subduction above it, with a degree- 1 structure initially forming at $400 \mathrm{Ma}$. At the same time, an equivalent antipodal structure in the African hemisphere is prevented to form because it is populated by subduction zones related to the closure of the Iapetus and Rheic oceans, as well as subduction between Laurussia and Gondwana (Figs 9, 10). Subduction in this region ceases at $\sim 300 \mathrm{Ma}$, and, mirroring the Paleozoic evolution of the sub-Pacific mantle, it takes nearly 150 million years in our model for a coherent, extensive hot basal structure to form underneath the remnants of Pangea in both models OPT1 and OPT2 (Fig. 9a, b). Large, coherent basal mantle structures thus only form when a lower mantle region is located distal to descending slabs for $\sim 150-200$ million years. In general terms, a reconstruction 
with a reference frame that seeks to stabilise trenches, as is the case in our optimised model, tends to stabilise mantle structuree. Alternative models with a different reference frame (but the same plate boundary configurations) are unlikely to do any better at generating stable deep mantle structures, as can be seen in the more mobile deep mantle structures resulting from the PMAG model (Supp. Animation S6).

The major changes in subduction geometry over the last $1 \mathrm{Gyr}$ therefore dictate that basal mantle structures are ephemeral, and constantly changing in response to subducting slabs pushing against their edges, or flowing over them (Fig. 13). Akin to the extremely heterogenous lower mantle structures seen in the seismic tomography images (e.g., Schuberth et al., 2009; Tkalčić et al., 2015) our model produces bundles of basal mantle upwellings very similar to the thermochemical upwellings enriched in denser than average material interpreted by Davaille and Romanowicz (2020) based on a combination of seismic tomography and fluid mechanic constraints (Fig. 12). In our mantle flow model basal mantle structures are always composed of a network of upwelling structures, from which mantle plumes are emanating. These networks may form and evolve without "LLSVP-like" extensive mantle upwellings, as is the case in our model from 1000-600 Ma, a period without either degree-1 or degree-2 lower mantle structures (Fig. 12, Supp. Animation S11). Their absence during this period reflects the widely distributed, rapidly evolving network of subduction zones, preventing 710 large coherent basal mantle structures to form (Figs 9, 12). Large basal structures form from the coalescence of distributed ridges and nodes, as they are being pushed towards each other by descending slabs in nearby regions (Fig. 12, Supp. Animation S11).

Most slabs descend into the lower mantle, but we find that slab stagnation occurs both in the transition zone as well as in the mid-lower mantle, around 1000-1400 km depth, as is observed in tomographic models (Shephard et al., 2017). The likelihood of stagnation at either depth appears to be increased by fast trench retreat/advance and/or subduction of relatively young lithosphere. Accumulations of slabs below the mid-lower mantle are often detached from shallower slabs and move laterally (Figs 10, 12, Supp. Animation S11). Therefore it cannot be expected that slab accumulations imaged in seismic tomography at depths far below $1400 \mathrm{~km}$ can be used as reliable markers for past locations of subduction zones, as implied in the subduction reference frame by Van Der Meer et al. (2010). Our mantle flow model further illustrates the effects of dynamic slab thickening and buckling (Lee and King, 2011) as slabs move from the transition zone into the lower mantle, and slabs also break off (Gerya et al., 2004; Von Blanckenburg and Davies, 1995 ) either when subduction ceases or due to rapid trench advance or retreat, or to a change in the sign of trench motion (e.g., from advance to retreat). When slabs reach the lowermost mantle, they move laterally towards upwelling regions, pushing hot, low-viscosity basal structures to form steep ridges along their margins (Supp. Animations S3, S4, S11). The coalescence of ridge-like upwellings that are being pushed towards each other by slabs results in enlarged structures with internal and marginal ridges (Fig 12, Supp. Animation S11). Slabs that have sunk to the lowermost mantle gradually heat up and occasionally rise and spread over the edge of basal mantle upwellings and mantle plumes form along basal ridges 
either in the interior or along the edges of basal mantle structures (Fig 12, Supp. Animation S11). The roots of individual plumes are not stationary but migrate in response to the deformation of basal structures, as found previously (e.g., Cao et al., 2021b; Hassan et al., 2016; Arnould et al., 2019). Plume tilt mostly forms in response to relatively fast plate motion and induced sub-horizontal lower mantle flow (Fig 12, Supp. Animation S11).

The spatial match between lower mantle temperature clusters of our preferred model OPT1 with tomographically-imaged lower mantle structure (Fig 13a) demonstrates that our model reproduces the observed largescale mantle structure quite well. It is noteworthy that the unoptimised model PMAG, not representing a mantle reference frame, reaches an equivalent accuracy to the optimised models OPT1 and OPT2 (Fig. 14a). This reflects that the presentday mantle structure is largely the result of the post-250 Ma subduction history (Flament, 2019) and that the unoptimised versus the optimised models do not show any dramatic differences in the position of plates and subduction zones during this time (compare reconstructions of the two models at $300 \mathrm{Ma}$ and $200 \mathrm{Ma}$ in Fig. 2a). The post-250 Ma differences in the subduction history between these models are not large enough to create any major dissimilarities between the modelled lower mantle structure at present-day. Stark differences between these plate models are confined to pre-300 Ma times (Fig. 2). The slightly larger excess density of the basal mantle layer in model OPT2 as compared to OPT1 (Table 1) results in a spatially more extensive basal mantle upwellings in OPT2 relative to OPT1 (Figs 9a, b, 13a, b). 745 This slightly improves the match to most seismic tomographic models in the African hemisphere in OPT2, while worsening the match in the Pacific hemisphere (Fig. 13b). In other words, in OPT2, the Pacific LLSVP is somewhat too extensive compared with tomographic images, while in OPT1 the African LLSVP is not sufficiently extensive, as reflected in the variation of the size of the areas labelled as true positive (Figs 13a, b). This may reflect that the excess density of the Pacific versus African LLSVPs is not identical, but further work, using more sophisticated mantle flow models, will be required to further investigate this inference.

Upper mantle temperature anomalies through time at $\sim 400 \mathrm{~km}$ depth (Fig. 11) illustrate that the largest anomalously hot upper mantle temperatures through time are associated with the formation of the degree-1 convection planform in the Pacific region around $400 \mathrm{Ma}$, spawning numerous plumes from an extensive network of upwelling basal mantle ridges (Fig. 11, Supp. Animation S11). However, as all ocean crust formed during this time is now subducted, it is difficult to find observational evidence supporting these model results, even though Doucet et al. (2020a) mapped a pulse of oceanic plume volcanism from 400-200 Ma based on ophiolite data, providing some circumstantial evidence in support of this model result. Cooler than average upper mantle temperatures are associated with continents overriding "slab burial grounds" (Fig. 11). Mapping such regions in the upper mantle is relevant for understanding magmatism related to upwellings originating from mantle transition zone regions enriched with volatiles from subducting slabs (e.g. Mather et al., 2020; Safonova et al., 2015). 
Extensive anomalously cool regions in the upper mantle occur in our model under Siberia, Baltica and North America (420-380 Ma, early to middle Devonian), North America (100-40 Ma, Late Cretaceous to Early Cenozoic) and along eastern/southern Asia and Zealandia (after $100 \mathrm{Ma}$ ) (Fig. 11). Devonian magmatism, including intraplate magmatism, in

765 Siberia, Baltica and North America was recently summarised by Ernst et al. (2020), and related to biotic crises. Nonplume related intraplate magmatism across this region may have been driven by subducted volatiles accumulating in the mantle transition zone under these continental regions and driving the formation of volatile-bearing transition zone plumes which have been related to both ocean island basalt-type mafic and felsic melts (Safonova et al., 2015). Post-100Ma subduction-related intraplate volcanism (including kimberlites) far inland from active trenches has been described both for North America (Currie and Beaumont, 2011; Heaman et al., 2003), eastern Asia (Cao et al., 2021c; Wu et al., 2005) and Zealandia (Mather et al., 2020; Mortimer and Scott, 2020).

\section{Conclusions}

We have used "tectonic rules" to optimise absolute mantle reference frame devoid of unreasonably large lithospheric net rotation, excessive subduction zone migration rates, and excessive speeds for plates hosting large continents. Both reconstructed latitudes and longitudes are optimised through time, avoiding the necessity to make assumptions such as the long-term stability of basal mantle structures which is in conflict with seismological observations and mantle flow models. Our model results in net rotation consistently below $0.25^{\circ} / \mathrm{Myr}$, while trench migration scatter is substantially reduced compared with the unoptimised model. Trench motion scatter is confined to a relatively narrow range during Pangea stability and dispersal, mostly between $-1 \mathrm{~cm} / \mathrm{yr}$ (trench advance) and $2 \mathrm{~cm} / \mathrm{yr}$ (trench retreat). In contrast, the period between $600 \mathrm{Ma}$ and $320 \mathrm{Ma}$ stands out as the most dynamic time in terms of ocean basin evolution and subduction zone migration in the last billion years, with relatively short, highly mobile subduction zones dominating - we propose to call this period the "zippy tricentenary". Our model independently confirms an orthoversion evolution from Rodinia to Pangea as proposed by Mitchell et al. (2012), but involving an eastward shift of their respective centres, not westward as previously suggested.

Our mantle flow model is driven by the imposed plate motions and subduction history and results in a succession of deep mantle states without or with large basal mantle structures akin to present-day LLSVPs. Our numerically modelled basal mantle structures bear a striking resemblance to the mantle tomographic images by Davaille and Romanowicz (2020). Their tomographic model, together with laboratory experiments, led to the view that LLSVPs are composed of bundles of thermochemical upwellings, whose shape is controlled by subduction history, resulting in a position and geometry of LLSVPs that are time dependent (Davaille and Romanowicz, 2020). This view is supported by our work, which explicitly links the evolution of the plates and plate boundaries over time with mantle structure evolution. Our model records five distinct intervals of mantle convection evolution over the last 1000 Myr. Initially, a broad network 
of basal ridges and nodes forms between $1000 \mathrm{Ma}$ and $600 \mathrm{Ma}$, followed by the formation of a short-lived degree- 2 basal mantle structure centred on the north and south pole between $600 \mathrm{Ma}$ and $500 \mathrm{Ma}$. It is superseded by a transitional phase during which the north polar basal structure migrates southward and gradually morphs into an extensive Pacificcentred basal structure while the south polar structure is dissected by subducting slabs and disintegrates into a network of ridges and nodes between 500-400 Ma. Subsequently a Pacific-centred degree-1 structure forms and is stable between $400 \mathrm{Ma}$ and $200 \mathrm{Ma}$, which is superseded by a basal degree-2 mantle structure after $\sim 160 \mathrm{Ma}$. This succession of mantle states is distinct from previously proposed models. Our Solid Earth Evolution Model for the last 1000 million years (SEEM1000) that can be analysed, tested and modified to provide insights into the history of magmatism, mineral resources, sea level change and biological evolution, forming the foundation for a multitude of spatio-temporal data analysis approaches.

\section{Code Availability}

The codes used for this paper are available on the public EarthByte and GPlates github sites. This includes absolute plate motion model optimisation code at https://github.com/EarthByte/optAPM, CitcomS software for mantle convection modelling at https://github.com/EarthByte/citcoms, and GPlates/pyGPlates at https://github.com/gplates for viewing and manipulating plate reconstructions.

\section{Data availability}

The optimised plate model, including paleo-oceanic crustal age grids, used in this paper is available on the EarthByte webdav site at https://www.earthbyte.org/webdav/ftp/Data_Collections/Muller_etal_2022_SE/. Mantle flow model configuration files and outputs are available on zenodo (see below).

\section{Video supplement}

Supplementary videos are available on zenodo (see below).

\section{Supplement link}

820 The data and video supplements are available on zenodo at 10.5281/zenodo.5801084.

\section{Author contribution}

RDM conceived and coordinated the research underpinning the paper, and wrote the manuscript. JC contributed to the design of the absolute plate model optimisation code, executed the optimisation runs and contributed to the manuscript.

825 MT wrote the original optimisation code and contributed to the manuscript. SEW contributed to the plate model optimisation code, wrote jupyter notebooks to visualise results, and contributed to manuscript. XC executed the mantle flow models, contributed to the analysis of the results and to the manuscript. NF oversaw the design of the mantle flow 
models, contributed to the model analysis and to the manuscript. OFB visualised the mantle flow models, SZ and AM contributed to the plate model and the manuscript.

\section{Competing interests}

The authors declare that they have no conflict of interest.

\section{Acknowledgments}

835 This research was supported by Australian Research Council grants LP210100173, LP170100863 and DE210100084 and supported by the Australian Government's National Collaborative Research Infrastructure Strategy (NCRIS), with access to computational resources provided by the National Computational Infrastructure (NCI) through the National Computational Merit Allocation Scheme and through the Sydney Informatics Hub HPC Allocation Scheme, which is supported by the Deputy Vice-Chancellor (Research), University of Sydney and ARC grant LE190100021.

Table 1. Parameters for mantle flow models

\begin{tabular}{|c|c|}
\hline Parameters & Value \\
\hline Initial slab depth & $1000 \mathrm{~km}$ \\
\hline Model warmup time & $250 \mathrm{Myr}$ \\
\hline Basal layer thickness & $113 \mathrm{~km}$ \\
\hline Reference viscosity & $1.1 \mathrm{e} 21 \mathrm{~Pa} \mathrm{~s}$ \\
\hline $\begin{array}{l}\text { Depth-dependent viscosity pre- } \\
\text { factor }\end{array}$ & $0.02,0.002,0.02,0.2$ (above $160 \mathrm{~km}, 160-310 \mathrm{~km}, 310-660 \mathrm{~km}$ and below $660 \mathrm{~km})$ \\
\hline $\begin{array}{l}\text { Compositional viscosity pre- } \\
\text { factor }\end{array}$ & $1,100,10$ for ambient mantle, continental lithosphere, and basal layer. \\
\hline $\begin{array}{l}\text { Temperature difference between } \\
\text { surface and CMB }\end{array}$ & $3100 \mathrm{~K}$ \\
\hline Rayleigh number & $7.8 \mathrm{e} 7$ \\
\hline Thermal diffusivity & $1 \mathrm{e}-6 \mathrm{~m}^{2} \mathrm{~s}^{-1}$ \\
\hline Dissipation number & 1.56 \\
\hline Buoyancy ratio for basal layer & $\begin{array}{l}\text { OPT1: } 0.25 \text { ( } 1 \% \text { excess density), OPT2, NNR, PMAG: } 0.325 \text { (1.3\% excess } \\
\text { density) }\end{array}$ \\
\hline $\begin{array}{l}\text { Hot basal structure (Paraview } \\
\text { visualization) }\end{array}$ & Mantle hotter than layer average by non-dimensional value $0.1(310 \mathrm{~K})$ \\
\hline Slab (Paraview visualization) & Mantle colder than layer average by non-dimensional value $0.05(155 \mathrm{~K})$ \\
\hline
\end{tabular}




\section{References}

Arnould, M., Ganne, J., Coltice, N., and Feng, X.: Northward drift of the Azores plume in the Earth's mantle, Nature communications, 10, 1-8, 2019.

Auer, L., Boschi, L., Becker, T., Nissen-Meyer, T., and Giardini, D.: Savani: A variable resolution whole-mantle model of anisotropic shear velocity variations based on multiple data sets, Journal of Geophysical Research: Solid Earth, 119, 3006-3034, 10.1002/2013JB010773, 2014.

Becker, T.: On the effect of temperature and strain-rate dependent viscosity on global mantle flow, net rotation, and platedriving forces, Geophysical Journal International, 167, 943-957, 2006.

850 Behn, M. D., Conrad, C. P., and Silver, P. G.: Detection of upper mantle flow associated with the African Superplume, Earth and Planetary Science Letters, 224, 259-274, 2004.

Bower, D. J., Gurnis, M., and Flament, N.: Assimilating lithosphere and slab history in 4-D Earth models, Physics of the Earth and Planetary Interiors, 238, 8-22, 10.1016/j.pepi.2014.10.013, 2015.

Brasier, M.: Secret chambers: the inside story of cells and complex life, OUP Oxford2012.

Bunge, H.-P., Richards, M. A., Lithgow-Bertelloni, C., Baumgardner, J. R., Grand, S. P., and Romanowicz, B. A.: Time scales and heterogeneous structure in geodynamic Earth models, Science, 280, 91-95, 1998.

Burke, K. and Torsvik, T. H.: Derivation of large igneous provinces of the past 200 million years from long-term heterogeneities in the deep mantle, Earth and Planetary Science Letters, 227, 531-538, 2004.

Butterworth, N., Talsma, A., Müller, R., Seton, M., Bunge, H.-P., Schuberth, B., Shephard, G., and Heine, C.: Geological, tomographic, kinematic and geodynamic constraints on the dynamics of sinking slabs, Journal of Geodynamics, 73, $1-13,2014$.

Cao, W., Flament, N., Zahirovic, S., Williams, S., and Müller, R. D.: The interplay of dynamic topography and eustasy on continental flooding in the late Paleozoic, Tectonophysics, 761, 108-121, 2019.

Cao, X., Flament, N., and Müller, R. D.: Coupled evolution of plate tectonics and basal mantle structure, Geochemistry, Geophysics, Geosystems, 22, e2020GC009244, 2021a.

Cao, X., Flament, N., Bodur, O., and Müller, R. D.: The evolution of basal mantle structure in response to supercontinent aggregation and dispersal, Scientific Reports, in press, $2021 \mathrm{~b}$.

Cao, X., Flament, N., Li, S., and Müller, R. D.: Spatio-temporal evolution and dynamic origin of Jurassic-Cretaceous magmatism in the South China Block, Earth-Science Reviews, 103605, 2021c.

Conrad, C. P. and Behn, M. D.: Constraints on lithosphere net rotation and asthenospheric viscosity from global mantle flow models and seismic anisotropy, Geochemistry, Geophysics, Geosystems, 11, 2010.

Cox, A. and Hart, R. B.: Plate tectonics: How it works, John Wiley \& Sons2009.

Currie, C. A. and Beaumont, C.: Are diamond-bearing Cretaceous kimberlites related to low-angle subduction beneath western North America?, Earth and Planetary Science Letters, 303, 59-70, 2011.

875 Davaille, A. and Romanowicz, B.: Deflating the LLSVPs: bundles of mantle thermochemical plumes rather than thick stagnant "piles", Tectonics, 39, e2020TC006265, 2020.

Davies, D., Goes, S., and Lau, H.: Thermally dominated deep mantle LLSVPs: a review, The Earth's heterogeneous mantle, 441-477, 2015.

Domeier, M. and Torsvik, T. H.: Plate tectonics in the late Paleozoic, Geoscience Frontiers, 5, 303-350, 2014.

880 Domeier, M., Doubrovine, P. V., Torsvik, T. H., Spakman, W., and Bull, A. L.: Global correlation of lower mantle structure and past subduction, Geophysical Research Letters, 43, 4945-4953, 2016.

Doucet, L. S., Li, Z.-X., Ernst, R. E., Kirscher, U., El Dien, H. G., and Mitchell, R. N.: Coupled supercontinent-mantle plume events evidenced by oceanic plume record, Geology, 48, 159-163, 2020a.

Doucet, L. S., Li, Z.-X., El Dien, H. G., Pourteau, A., Murphy, J. B., Collins, W. J., Mattielli, N., Olierook, H. K., Spencer,

885 C. J., and Mitchell, R. N.: Distinct formation history for deep-mantle domains reflected in geochemical differences, Nature Geoscience, 13, 511-515, 2020b.

Dziewonski, A. M. and Anderson, D. L.: Preliminary reference Earth model, Physics of the earth and planetary interiors, 25, 297-356, 1981.

Ernst, R. E., Rodygin, S. A., and Grinev, O. M.: Age correlation of Large Igneous Provinces with Devonian biotic crises, Global and Planetary Change, 185, 103097, 2020. 
Evans, D., Li, Z.-X., and Murphy, J.: Four-dimensional context of Earth's supercontinents, Geological Society, London, Special Publications, 424, 1-14, 2016.

Flament, N.: Present-day dynamic topography and lower-mantle structure from palaeogeographically constrained mantle flow models, Geophysical Journal International, 216, 2158-2182, 2019.

Flament, N., Williams, S., Muller, R. D., Gurnis, M., and Bower, D. J.: Origin and evolution of the deep thermochemical structure beneath Eurasia, Nature Communications, 8, 14164, 10.1038/ncomms 14164, 2017.

French, S. W. and Romanowicz, B. A.: Whole-mantle radially anisotropic shear velocity structure from spectral-element waveform tomography, Geophysical Journal International, 199, 1303-1327, 10.1093/gji/ggu334, 2014.

Garnero, E. J. and McNamara, A. K.: Structure and dynamics of Earth's lower mantle, science, 320, 626-628, 2008.

Gerya, T. V., Yuen, D. A., and Maresch, W. V.: Thermomechanical modelling of slab detachment, Earth and Planetary Science Letters, 226, 101-116, 2004.

Gurnis, M., Turner, M., Zahirovic, S., DiCaprio, L., Spasojevic, S., Muller, R., Boyden, J., Seton, M., Manea, V., and Bower, D.: Plate tectonic reconstructions with continuously closing plates, Computers and Geosciences, 38, 35-42, 2012.

905 Hassan, R., Müller, R. D., Gurnis, M., Williams, S. E., and Flament, N.: A rapid burst in hotspot motion through the interaction of tectonics and deep mantle flow, Nature, 533, 239-242, 2016.

Heaman, L. M., Kjarsgaard, B. A., and Creaser, R. A.: The timing of kimberlite magmatism in North America: implications for global kimberlite genesis and diamond exploration, Lithos, 71, 153-184, 2003.

$910 \quad 129-155,2002$

Houser, C., Masters, G., Shearer, P., and Laske, G.: Shear and compressional velocity models of the mantle from cluster analysis of long-period waveforms, Geophysical Journal International, 174, 195-212, 10.1111/j.1365246X.2008.03763.x, 2008.

Kocsis, Á. T. and Scotese, C. R.: Mapping paleocoastlines and continental flooding during the Phanerozoic, EarthScience Reviews, 213, 103463, 2021.

Koppers, A. A., Becker, T. W., Jackson, M. G., Konrad, K., Müller, R. D., Romanowicz, B., Steinberger, B., and Whittaker, J. M.: Mantle plumes and their role in Earth processes, Nature Reviews Earth \& Environment, 2, 382$401,2021$.

Kreemer, C. and Holt, W. E.: A no-net-rotation model of present-day surface motions, Geophysical Research Letters, 28, 4407-4410, 2001.

Kustowski, B., Ekström, G., and Dziewoński, A. M.: Anisotropic shear-wave velocity structure of the Earth's mantle: A global model, Journal of Geophysical Research, 113, 10.1029/2007jb005169, 2008.

Le Pichon, X., Şengör, A. C., and İmren, C.: Pangea and the lower mantle, Tectonics, 38, 3479-3504, 2019.

Le Pichon, X., Jellinek, M., Lenardic, A., Şengör, A. C., and İmren, C.: Pangea Migration, Tectonics, 40, e2020TC006585, 2021.

Lee, C. and King, S. D.: Dynamic buckling of subducting slabs reconciles geological and geophysical observations, Earth and Planetary Science Letters, 312, 360-370, 2011.

Lekic, V., Cottaar, S., Dziewonski, A., and Romanowicz, B.: Cluster analysis of global lower mantle tomography: A new class of structure and implications for chemical heterogeneity, Earth and Planetary Science Letters, 357-358, 68-77,

$930 \quad$ 10.1016/j.eps1.2012.09.014, 2012.

MacQueen, J.: Some methods for classification and analysis of multivariate observations, Proceedings of the fifth Berkeley symposium on mathematical statistics and probability, 281-297,

Maher, S., Wessel, P., Müller, R., Williams, S., and Harada, Y.: Absolute plate motion of Africa around Hawaii-Emperor bend time, Geophysical Journal International, 201, 1743-1764, 2015.

935 Mao, W. and Zhong, S.: Constraints on Mantle Viscosity From Intermediate-Wavelength Geoid Anomalies in Mantle Convection Models With Plate Motion History, Journal of Geophysical Research: Solid Earth, 126, e2020JB021561, 2021.

Mather, B. R., Müller, R. D., Seton, M., Ruttor, S., Nebel, O., and Mortimer, N.: Intraplate volcanism triggered by bursts in slab flux, Science advances, 6, eabd0953, 2020. 
https://doi.org/10.5194/se-2021-154

Preprint. Discussion started: 26 January 2022

(c) Author(s) 2022. CC BY 4.0 License.

940 Matthews, K. J., Maloney, K. T., Zahirovic, S., Williams, S. E., Seton, M., and Mueller, R. D.: Global plate boundary evolution and kinematics since the late Paleozoic, Global and Planetary Change, 146, 226-250, 2016.

McNamara, A. K. and Zhong, S.: Thermochemical structures within a spherical mantle: Superplumes or piles?, Journal of Geophysical Research: Solid Earth, 109, 2004.

Mégnin, C. and Romanowicz, B.: The three-dimensional shear velocity structure of the mantle from the inversion of body, surface and higher-mode waveforms, Geophysical Journal International, 143, 709-728, 10.1046/j.1365246x.2000.00298.x 2000.

Merdith, A. S., Williams, S. E., Collins, A. S., Tetley, M. G., Mulder, J. A., Blades, M. L., Young, A., Armistead, S. E., Cannon, J., and Zahirovic, S.: Extending full-plate tectonic models into deep time: Linking the Neoproterozoic and the Phanerozoic, Earth-Science Reviews, 103477, 2021.

950 Mitchell, R. N.: True polar wander and supercontinent cycles: Implications for lithospheric elasticity and the triaxial Earth, American Journal of Science, 314, 966-979, 2014.

Mitchell, R. N., Kilian, T. M., and Evans, D. A.: Supercontinent cycles and the calculation of absolute palaeolongitude in deep time, Nature, 482, 208-211, 2012.

Mortimer, N. and Scott, J. M.: Volcanoes of Zealandia and the southwest Pacific, New Zealand Journal of Geology and

\section{Geophysics, 63, 371-377, 2020.}

Müller, R. D., Seton, M., Zahirovic, S., Williams, S. E., Matthews, K. J., Wright, N. M., Shephard, G. E., Maloney, K. T., Barnett-Moore, N., and Hosseinpour, M.: Ocean basin evolution and global-scale plate reorganization events since Pangea breakup, Annual Review of Earth and Planetary Sciences, 44, 107-138, 2016.

Murphy, J. B. and Nance, R. D.: Do supercontinents introvert or extrovert?: Sm-Nd isotope evidence, Geology, 31, 873$876,2003$.

Murphy, J. B., Nance, R. D., and Cawood, P. A.: Contrasting modes of supercontinent formation and the conundrum of Pangea, Gondwana Research, 15, 408-420, 2009.

O'Neill, C., Müller, R. D., and Steinberger, B.: On the uncertainties in hot spot reconstructions and the significance of moving hot spot reference frames, Geochemistry, Geophysics, Geosystems, 6, 2005.

965 Raub, T., Kirschvink, J., and Evans, D.: True polar wander: linking deep and shallow geodynamics to hydro-and biospheric hypotheses, Treatise on geophysics, 5, 565-589, 2007.

Ricard, Y., Doglioni, C., and Sabadini, R.: Differential rotation between lithosphere and mantle: a consequence of lateral mantle viscosity variations, Journal of Geophysical Research: Solid Earth, 96, 8407-8415, 1991.

Ritsema, J., Deuss, a. A., Van Heijst, H., and Woodhouse, J.: S40RTS: a degree-40 shear-velocity model for the mantle from new Rayleigh wave dispersion, teleseismic traveltime and normal-mode splitting function measurements, Geophysical Journal International, 184, 1223-1236, 10.1111/j.1365-246x.2010.04884.x 2011.

Rudolph, M. L. and Zhong, S.: History and dynamics of net rotation of the mantle and lithosphere, Geochemistry, Geophysics, Geosystems, 15, 3645-3657, 2014.

Safonova, I., Litasov, K., and Maruyama, S.: Triggers and sources of volatile-bearing plumes in the mantle transition zone, Geoscience Frontiers, 6, 679-685, 2015.

Schellart, W., Stegman, D., and Freeman, J.: Global trench migration velocities and slab migration induced upper mantle volume fluxes: Constraints to find an Earth reference frame based on minimizing viscous dissipation, Earth-Science Reviews, 88, 118-144, 2008.

Schellart, W. P., Freeman, J., Stegman, D. R., Moresi, L., and May, D.: Evolution and diversity of subduction zones controlled by slab width, Nature, 446, 308-311, 2007.

Schuberth, B. S., Bunge, H. P., and Ritsema, J.: Tomographic filtering of high-resolution mantle circulation models: Can seismic heterogeneity be explained by temperature alone?, Geochemistry, Geophysics, Geosystems, $10,2009$.

Shephard, G. E., Matthews, K. J., Hosseini, K., and Domeier, M.: On the consistency of seismically imaged lower mantle slabs, Scientific reports, 7, 1-17, 2017.

Simmons, N. A., Forte, A. M., Boschi, L., and Grand, S. P.: GyPSuM: A joint tomographic model of mantle density and seismic wave speeds, Journal of Geophysical Research: Solid Earth, 115, 10.1029/2010JB007631, 2010.

Sobolev, S. V. and Brown, M.: Surface erosion events controlled the evolution of plate tectonics on Earth, Nature, 570, 52-57, 2019. 
Steinberger, B.: Plumes in a convecting mantle: Models and observations for individual hotspots, Journal of Geophysical Research: Solid Earth, 105, 11127-11152, 2000.

Tackley, P. J. and King, S. D.: Testing the tracer ratio method for modeling active compositional fields in mantle convection simulations, Geochemistry, Geophysics, Geosystems, 4, 2003.

Tetley, M. G., Williams, S. E., Gurnis, M., Flament, N., and Müller, R. D.: Constraining absolute plate motions since the Triassic, Journal of Geophysical Research: Solid Earth, 124, 7231-7258, 2019.

995 Tkalčić, H., Young, M., Muir, J. B., Davies, D. R., and Mattesini, M.: Strong, multi-scale heterogeneity in Earth's lowermost mantle, Scientific reports, 5, 1-8, 2015.

Torsvik, T. H. and Cocks, L. R. M.: The integration of palaeomagnetism, the geological record and mantle tomography in the location of ancient continents, Geological Magazine, 156, 242-260, 2019.

$1000 \quad$ unified model, Reviews of geophysics, 46, 2008.

Van Der Meer, D. G., Spakman, W., Van Hinsbergen, D. J., Amaru, M. L., and Torsvik, T. H.: Towards absolute plate motions constrained by lower-mantle slab remnants, Nature Geoscience, 3, 36-40, 2010.

van Hinsbergen, D. J., De Groot, L. V., van Schaik, S. J., Spakman, W., Bijl, P. K., Sluijs, A., Langereis, C. G., and Brinkhuis, H.: A paleolatitude calculator for paleoclimate studies, PloS one, 10, e0126946, 2015.

von Blanckenburg, F. and Davies, J. H.: Slab breakoff: a model for syncollisional magmatism and tectonics in the Alps, Tectonics, 14, 120-131, 1995.

Wessel, P. and Kroenke, L. W.: Pacific absolute plate motion since 145 Ma: An assessment of the fixed hot spot hypothesis, Journal of Geophysical Research: Solid Earth, 113, 2008.

Williams, S., Wright, N. M., Cannon, J., Flament, N., and Müller, R. D.: Reconstructing seafloor age distributions in lost ocean basins, Geoscience Frontiers, 12, 769-780, 2021.

Williams, S. E., Flament, N., Müller, R. D., and Butterworth, N.: Absolute plate motions since 130 Ma constrained by subduction zone kinematics, Earth and Planetary Science Letters, 418, 66-77, 2015.

Wu, F.-Y., Lin, J.-Q., Wilde, S. A., and Yang, J.-H.: Nature and significance of the Early Cretaceous giant igneous event in eastern China, Earth and Planetary Science Letters, 233, 103-119, 2005.

1015 Zahirovic, S., Müller, R. D., Seton, M., and Flament, N.: Tectonic speed limits from plate kinematic reconstructions, Earth and Planetary Science Letters, 418, 40-52, 2015.

Zhang, N., Zhong, S., Leng, W., and Li, Z. X.: A model for the evolution of the Earth's mantle structure since the Early Paleozoic, Journal of Geophysical Research: Solid Earth, 115, 2010.

Zhong, S. and Liu, X.: The long-wavelength mantle structure and dynamics and implications for large-scale tectonics

1020 and volcanism in the Phanerozoic, Gondwana Research, 29, 83-104, 2016. early P aleozoic, Geochemistry, Geophysics, Geosystems, 16, 1599-1615, 2015.

Zhong, S., Zhang, N., Li, Z.-X., and Roberts, J. H.: Supercontinent cycles, true polar wander, and very long-wavelength mantle convection, Earth and Planetary Science Letters, 261, 551-564, 2007.

1025 Zhong, S., McNamara, A., Tan, E., Moresi, L., and Gurnis, M.: A benchmark study on mantle convection in a 3-D spherical shell using CitcomS, Geochemistry, Geophysics, Geosystems, 9, 2008. 